\title{
Legitimation güterrechtlicher Teilhabe im Spannungsverhältnis von Solidarität und Individualisierung
}

\author{
Stephan Meder/Christoph-Eric Mecke*
}
A. Problemstellung
B. Konsensuale oder normative Legitima- tion güterrechtlicher Teilhabe .........
C. Legitimation güterrechtlicher Teilhabe in der Geschichte des Ehegüterrechts . .
D. Drei Begründungsmodelle zur heutigen Legitimation des Umfangs güterrecht- licher Teilhabe
I. Begründungsmodell güterrechtlicher Teilhabe aufgrund des Bestehens einer Solidargemeinschaft

1

II. Begründungsmodell güterrechtlicher Teilhabe aufgrund der Mitverursachung von Vermögensvorteilen......

III. Begründungsmodell güterrechtlicher Teilhabe aufgrund einer Kompensation ehe- und partnerschaftsbedingter Nachteile ........................ 21

E. Resümee

\section{A. Problemstellung}

Das geltende Güterrecht für Eheleute und in Deutschland seit 2001 auch für gleichgeschlechtliche Partner einer eingetragenen Lebenspartnerschaft gerät seit einigen Jahren immer stärker in die rechtswissenschaftliche Diskussion. Aktueller Anlass sind akademische, aber auch politische Initiativen zu einer Einbeziehung des Güterrechts in den Prozess europäischer Rechtsharmonisierung. Anfang 2013 hat die Commission on European Family Law (CEFL) - eine unabhängige Vereinigung von Wissenschaftler/innen aus mehr als zwei Dutzend europäischen Ländern ${ }^{1}$ - für die künftige güterrechtliche Entwicklung in Europa „Principles of European Family Law Regarding Property Relations between Spouses“ formuliert, die auf der Grundlage einer Bestandsaufnahme güterrechtlicher Regelungen in europäischen Ländern erarbeitet wurden. ${ }^{2}$ Im Mai 2013 trat mit dem deutsch-französischen Güterstand der Wahl-Zugewinngemeinschaft in Europa erstmals ein in zwei Staaten einheitlich geltender Güterstand in Kraft. ${ }^{3}$ Er wurde angesichts fehlender europarechtlicher Kompetenzen für das materielle Familienrecht in einer bisher beispiellosen rechtspoliti-

* Professor Dr. Stephan Meder ist Inhaber des Lehrstuhls für Zivilrecht und Rechtsgeschichte an der Leibniz Universität Hannover. Dr. Christoph-Eric Mecke ist wissenschaftlicher Mitarbeiter an diesem Lehrstuhl.

1 D.Martiny, Europäisches Güterrecht? Die Arbeit der CEFL, in: Volker Lipp/Eva Schumann/Barbara Veit (Hrsg.), Die Zugewinngemeinschaft - ein europäisches Modell? 7. Göttinger Workshop zum Familienrecht 2008, Göttingen 2009, S. 39 (43).

2 K.Boele-Woelki et al. (Hrsg.), Principles of European Family Law Regarding Property Relations between Spouses, Cambridge/Antwerp/Portland 2013, S. 31-356.

3 D.Martiny, Der neue deutsch-französische Wahlgüterstand - Ein Beispiel optionaler bilateraler Familienrechtsvereinheitlichung, ZEuP 2011, S. 577-600; C.-E.Mecke, Güterrechtliche Grundsatzfragen. Zur Legitimation und Dogmatik güterrechtlicher Teilhabe im Zeichen gesellschaftlichen Wandels und europäischer Harmonisierungsbestrebungen, AcP 211 (2011), S. 886 (899-916); N.Dethloff, Der deutschfranzösische Wahlgüterstand. Wegbereiter für eine Angleichung des Familienrechts?, RabelsZ 76 (2012), S. 509-539. 
schen Initiative der deutschen und französischen Regierung durch einen Staatsvertrag vereinbart und steht nun weiteren europäischen Staaten zur Kooption offen.

Auch im nationalen Rahmen ist das deutsche Güterrecht seit ungefähr zwanzig Jahren ${ }^{4}$ erneut $^{5}$ Gegenstand von grundsätzlichen Überlegungen und Kontroversen. So konstatierte Dieter Schwab bereits im Jahre 2000, dass aus der „kontroversen Behandlung einiger Spezialprobleme" mit dem gesetzlichen Güterstand der Zugewinngemeinschaft, der in Deutschland seit 1958 für den ganz überwiegenden Teil der Ehen die spezifisch familienrechtliche Vermögensordnung unter den Eheleuten regelt, „mehr und mehr eine Diskussion um den Güterstand im ganzen“ geworden sei. ${ }^{6}$ Einen untrüglichen Hinweis darauf, dass die Gründe für diese Diskussion tiefer liegen, ergibt sich aus der Tatsache, dass während der Verhandlungen des 67. Juristentages von 2008 in der Abteilung Zivilrecht ein Gutachten im Mittelpunkt der Diskussion stand, das alle drei in Deutschland geltenden familienrechtlichen Ausgleichssysteme, Güterrecht, Unterhaltsrecht und Versorgungsausgleich, auf den Prüfstand stellte. Die gutachterliche Ausgangsfrage lautete: „Sind unsere familienrechtlichen Ausgleichssysteme noch zeitgemäß? “ Angesichts des nicht nur in Deutschland zu konstatierenden Rückgangs der klassischen Versorgerehe mit männlichem Alleinverdiener bei gleichzeitig zunehmender Berufstätigkeit von Frauen, der Pluralisierung familiärer Lebensformen sowie steigenden Scheidungszahlen stellt sich die Frage: „Was rechtfertigt überhaupt Ausgleichszahlungen nach Beendigung einer Partnerschaft? "7 Diese Frage stellt sich umso dringlicher, als nach jüngeren sozialempirischen Erhebungen die Bereitschaft zur Übernahme nachehelicher Solidaritätspflichten immer stärker sinkt. ${ }^{8}$ Vor allem für den Fall der Beendigung der Ehe

4 Vgl. etwa S.Urbach, Unzulänglichkeiten der Zugewinngemeinschaft. Reformvorschlag für den gesetzlichen Ehegüterstand der Bundesrepublik Deutschland anhand fremder Rechtssysteme, Frankfurt a.M. 1990; R.Battes, Ehegewinn und eheneutraler Erwerb. Eine Grundsatzfrage des gesetzlichen Güterrechts, in: F.W.Bosch (Hrsg.), Neuere Entwicklungen im Familienrecht. Symposion aus Anlaß des 80. Geburtstages von Günther Beitzke, Berlin 1990, S. 49-62; ders., Sinn und Grenzen des Zugewinnausgleichs, FuR 1990, S. 311-324. In der Zeit nach 1990 ist die Grundsatzdebatte zum Güterrecht, zeitweilig zusätzlich angeregt durch die güterrechtlichen Anpassungsfragen im Zuge der deutschen Wiedervereinigung, nicht mehr zum Erliegen gekommen.

5 Nach den Kontroversen um den familienrechtlichen Teil des BGB in den 1890er Jahren war das Güterrecht zuletzt in den 1920er und 1950er Jahren Gegenstand familienrechtspolitischer Grundsatzdiskussionen in Deutschland (vgl. nur S.Meder, Familienrecht. Von der Antike bis zur Gegenwart, Köln/ Weimar/Wien 2013, S. 193-197, 221-226).

6 D.Schwab, Der Zugewinnausgleich in der Krise, in: G.Köbler/M.Heinze/W.Hromadka (Hrsg.), Europas universale rechtsordnungspolitische Aufgabe im Recht des dritten Jahrtausends. Festschrift für Alfred Söllner zum 70. Geburtstag, München 2000, S. 1079 (1080).

7 N.Dethloff, Unterhalt, Zugewinn, Versorgungsausgleich - Sind unsere familienrechtlichen Ausgleichssysteme noch zeitgemäß? Gutachten A für den 67. Deutschen Juristentag, in: Ständige Deputation des Deutschen Juristentages (Hrsg.), Verhandlungen des Siebenundsechzigsten Deutschen Juristentages. Band I, München 2008, S. 10.

8 Bundesministerium für Familie, Senioren, Frauen und Jugend (BMFSFJ) (Hrsg.), Sinus Sociovision. Partnerschaft und Ehe - Entscheidungen im Lebensverlauf. Einstellungen, Motive, Kenntnisse des rechtlichen Rahmens, Berlin 2010, S. 12, 16, 21, 54-57, 63. 
durch Scheidung sind alle drei Säulen der in Deutschland geltenden familienrechtlichen Ausgleichssysteme von den veränderten Einstellungen betroffen.

Das Bundesverfassungsgericht geht in ständiger Rechtsprechung davon aus, dass „beide Ehegatten grundsätzlich [...] Anspruch auf gleiche Teilhabe am gemeinsam Erwirtschafteten“ hätten, da „die Leistungen, die sie jeweils im Rahmen der von ihnen in gemeinsamer Entscheidung getroffenen Arbeits- und Aufgabenzuweisung erbringen, als gleichwertig anzusehen " seien. ${ }^{9}$ Der Begriff der Teilhabe ${ }^{10}$ betrifft danach nicht zuletzt das Güterrecht, das - sofern nicht ausnahmsweise ehevertraglich Gütertrennung vereinbart wurde - die Verteilung der gemeinsam erwirtschafteten Vermögenswerte unter den Eheleuten oder Lebenspartnern einer eingetragenen Lebenspartnerschaft regelt. Im Einzelnen bestimmen die europäischen Güterrechtsordnungen unterschiedliche Formen wechselseitiger Teilhabe unter den Güterstandsbeteiligten im Hinblick auf den Zeitpunkt und die Art der Teilhabe an den Vermögensaktiva während der Dauer des Güterstandes und nach dessen Beendigung, ferner den Grad der Teilhabe an den vermögensrechtlich relevanten Entscheidungen des anderen sowie - als Gegenstück dazu - die Teilhabe an der Haftung im Verhältnis gegenüber Dritten sowie an der Belastung mit Verbindlichkeiten im Verhältnis zwischen beiden Güterstandsbeteiligten. ${ }^{11}$

An erster Stelle ist im Güterrecht aber immer zunächst zu klären, welchen legitimatorischen Grund und welchen wertmäßigen Umfang güterrechtliche Vermögensteilhabe überhaupt haben soll. Die Legitimation wechselseitiger Teilhabe an ehe- oder partnerschaftszeitlich erworbenem Vermögen bildet für alle Güterrechtsordnungen eine fundamentale Frage, sie soll im Folgenden näher beleuchtet werden. Nicht erörtert werden soll an dieser Stelle hingegen die erst in einem zweiten Schritt zu beantwortende Frage nach der angemessenen Form der Vermögensteilhabe, ${ }^{12}$ sie richtet sich maßgeblich nach dem jeweiligen Güterstandstypus. Insoweit bestehen prin-

9 BVerfGE 105, 1 (11f.) = FamRZ 2002, S. 527 (529); BVerfG FamRZ 2003, S. 1173.

10 Vgl. nur grundsätzlich U.Diederichsen, Teilhabegerechtigkeit in der Ehe, in: Neunter Deutscher Familiengerichtstag, Bielefeld 1992, S. 17-46 m.w.N., ferner zur Frage ehevertraglicher Abdingbarkeit güterrechtlicher Teilhabe B.Dauner-Lieb/A.Sanders, Abdingbare Teilhabe - unabdingbare Verantwortung? Grenzen güterrechtlicher Vereinbarungen im Lichte der Rechtsprechung des BVerfG und des BGH, FPR 2005, S. 141 (142-146).

11 S.Meder, Individualisierung von Lebensverläufen und Verantwortungskooperationen. Herausforderungen eines geschlechtergerechten Ehe-, Partnerschafts- und Familienrechts, Jahrbuch für Christliche Sozialwissenschaften 53 (2012), S. 139 (165); B.Dauner-Lieb, Anforderungen an ein Konzept für einen Güterstand der Errungenschaftsgemeinschaft in Deutschland - Thesen und offene Fragen, in: G.Brudermüller/B.Dauner-Lieb/S.Meder (Hrsg.), Wer hat Angst vor der Errungenschaftsgemeinschaft. Auf dem Weg zu einem partnerschaftlichen Güterrecht, Göttingen 2013, S. 47 (58-64) sowie Mecke, Grundsatzfragen (Fn. 3), S. 892; ders., Zwölf Thesen zu einem künftigen Güterrecht in Deutschland, in: G.Brudermüller/B.Dauner-Lieb/S.Meder (Hrsg.), Errungenschaftsgemeinschaft (aaO), S. 124-132 zu den drei zu unterscheidenden Aspekten güterrechtlicher Teilhabe.

12 Vgl. nur Schwab, Zugewinnausgleich (Fn. 6), S. 1079-1093; A.Röthel, Plädoyer für eine echte Zugewinngemeinschaft. Bemerkungen anlässlich des Regierungsentwurfs zur Änderung des Zugewinnausgleichs, FPR 6 (2009), S. 273-276; Brudermüller/Dauner-Lieb/Meder (Hrsg.), Errungenschaftsgemeinschaft (Fn. 11). 
zipielle Unterschiede zwischen den in den europäischen Rechtsordnungen geltenden Güterrechtstypen. ${ }^{13}$ Während bei Güterständen wie der Zugewinngemeinschaft, die auf dem Grundtypus der Gütertrennung beruhen, die Entscheidungs- und die Haftungsteilhabe eine geringere Rolle spielen, ${ }^{14}$ bilden die entsprechenden Regelungen bei Güterständen nach dem Grundtypus der Gütergemeinschaft, heute zumeist Errungenschaftsgemeinschaften, ein mit der Vermögensteilhabe ausgeklügeltes güterrechtliches Regime zur Regelung der vermögensrechtlichen Beziehungen der Güterstandsbeteiligten im Innen- und im Außenverhältnis. ${ }^{15}$ Hingegen gehört der wertmäßige Umfang der Vermögensteilhabe zum Bereich „funktionaler Äquivalenz“16 unabhängig von der Zugehörigkeit des jeweiligen Güterstands zu einem bestimmten Güterrechtstyp.

Im Folgenden wird zunächst einleitend skizziert, welche Anknüpfungspunkte für die Legitimation gesetzlich bestimmter Vermögensteilhabe grundsätzlich in Betracht kommen (B). Anschließend werden zentrale Legitimationstopoi aus der Geschichte des Ehegüterrechts bis zur Gesetzgebungsgeschichte des heute in Deutschland geltenden gesetzlichen Güterstandes vorgestellt (C). Der zweite Teil des Beitrags widmet sich der gegenwärtig geführten Grundsatzdiskussion zur Legitimation güterrechtlicher Teilhabe (D). In dieser Diskussion lassen sich drei prinzipiell zu unterscheidende Begründungsmodelle erkennen (D. I.-III.). Ein Resümee beschließt den Beitrag (E).

\section{B. Konsensuale oder normative Legitimation güterrechtlicher Teilhabe}

Sucht man nach möglichen Gründen zur Legitimation von gesetzlich bestimmter güterrechtlicher Teilhabe, so könnte man zunächst an die Anknüpfung an bestimmte Ehetypen in der familiären Lebenswirklichkeit denken. Aber abgesehen davon, dass ein - zumal gesetzlicher - Güterstand nicht nur für einen Ehetyp angemessen sein darf, kann die für die notarielle Praxis von Eheverträgen durchaus sinnvolle Fall-

13 Vgl. zu den Güterrechtsordnungen in Europa nur die Überblicke bei W.Pintens, Ehegüterstände in Europa, in: V.Lipp/E.Schumann/B.Veit (Hrsg.), Die Zugewinngemeinschaft - ein europäisches Modell? 7. Göttinger Workshop zum Familienrecht 2008, Göttingen 2009, S. 23-37; D.Henrich (Hrsg.), Eheliche Gemeinschaft, Partnerschaft und Vermögen im europäischen Vergleich, Bielefeld 1999; ders., Zur Zukunft des Güterrechts in Europa, FamRZ 2002, S. 1521-1526; ferner auch rechtsvergleichend Mecke, Thesen (Fn. 11), S. 111-185.

14 Vgl. etwa zur Entscheidungs- und Haftungsteilhabe im deutschen gesetzlichen Güterstand der Zugewinngemeinschaft die $\mathbb{S} \mathbb{S} 1365-1369$ BGB sowie güterstandsübergreifend $\mathbb{} 1357 \mathrm{BGB}$. Hinzu kommen unterhalb der Schwelle der aktiven Teilhabe an den vermögensrechtlichen Entscheidungen des anderen Güterstandsbeteiligten mittelbare Beschränkungen der Freiheit, unkontrolliert über das eigene Vermögen disponieren zu können.

15 Vgl. beispielsweise nur die Vorschriften des in Frankreich geltenden gesetzlichen Güterstandes der Errungenschaftsgemeinschaft (communauté des acquêts) einerseits zum Aktiv-, andererseits zum Passivvermögen der Gemeinschaft (Art. 1401-1418 Code civil), ferner zur Verwaltung des Gesamtguts und der Eigengüter (Art. 1421-1440 Code civil) sowie die Regelungen zur Vermögens- und Haftungsteilhabe nach Beendigung des Güterstandes (Art. 1467-1491 Code civil).

16 D.Martiny, Schlussfolgerungen aus familienvergleichender Perspektive, in: BMFSFJ (Hrsg.), Dokumentation der Tagung „Eigenverantwortung, private und öffentliche Solidarität - Rollenleitbilder im Familien- und Sozialrecht im europäischen Vergleich“, Baden-Baden 2008, S. 429 (437). 
gruppenbildung ${ }^{17}$ zwar unterschiedliche Interessen typisieren, nicht aber Legitimationsgründe und damit einen Interessenmaßstab liefern. Die Frage nach Legitimationsgründen für die Zuschreibung von Vermögensvorteilen lässt sich wie alle normativen Fragen niemals endgültig entscheiden, wohl aber kann man eine im Lichte des sozialen Wandels immer von neuem zu überprüfende Antwort in einem jeweils höheren oder geringeren Maße plausibel machen. Die Darlegung hinreichender Plausibilität für die Legitimation güterrechtlicher Teilhabe kann grundsätzlich auf zwei Wegen erfolgen, nämlich entweder durch rechtsethische Begründungsmodelle oder durch konsensuale Akzeptanz, mithin Zustimmung der Betroffenen. Beide Wege schließen sich nicht gegenseitig aus, sondern können sich wechselseitig ergänzen und gegebenenfalls auch beschränken.

Besonders hoch ist der Legitimationsgrad für eine Regelung im Falle konsensualer Akzeptanz, da die Legitimation hier direkt an die Willen der Betroffenen selbst anknüpft. Die Zuschreibung von Rechten und Rechtspflichten aufgrund freier und eigenverantwortlicher Selbstbindung durch entsprechende Willensäußerung ist Ausdruck des grundlegenden Prinzips privatrechtlicher Zurechnung in einem auf Privatautonomie beruhenden Rechtssystem. Der Legitimationsgrad wechselseitiger freier Selbstbindung ist sogar so hoch, dass durch die freie Selbstbindung grundsätzlich auch bereits die immanente Richtigkeit der Inhalte der Willensübereinstimmung als Vertragsgerechtigkeit indiziert ist. Nur in besonderen Ausnahmefällen sprechen auf Privatautonomie beruhende Rechtsordnungen den inhaltlichen Ergebnissen von Willensübereinstimmungen die Legitimität etwa wegen groben Verstoßes gegen das aus dem Gerechtigkeitsmodell der kommutativen Gerechtigkeit folgende Äquivalenzprinzip ab. ${ }^{18}$ Ein rechtsethischer Grund für güterrechtliche Teilhabe lässt sich auf diesem Wege aber allenfalls für ehevertraglich bestimmte Wahlgüterstände, nicht hingegen für güterrechtliche Teilhabe aufgrund eines von Gesetzes wegen eintretenden gesetzlichen Güterstandes gewinnen.

Güterrechtliche Teilhabe im Rahmen eines gesetzlichen Güterstandes zu legitimieren, ist mithin schwieriger, nach Ansicht mancher Kritiker sogar ganz unmöglich. ${ }^{19}$ Auf jeden Fall kommen nur überindividuelle Zurechnungsmodelle in Betracht, also all-

17 Vgl. nur G.Langenfeld, Ehevertragsgestaltung. Zur Fallgruppenbildung in der Kautelarjurisprudenz, FamRZ 1987, S. 9 (11-13), der zehn Ehetypen unterscheidet (Einverdienerehe mit Kindern, Partnerschaftsehe berufstätiger kinderloser Eheleute, Ehen mit erheblichem Anfangsvermögen oder zu erwartendem privilegierten Erwerb etc.).

18 Dazu auch aus rechtshistorischer Perspektive E.Koch, Vertragsgerechtigkeit - Rechtshistorische Betrachtungen, in: M.Bengel et al. (Hrsg.), Festschrift für Rainer Kanzleiter zum 70. Geburtstag, Köln 2010, S. 237-246.

19 So wäre nach K.Muscheler, Familienrecht, Neuwied 2006, S. 171 Rn. 336 a.E. die „richtige Lösung“ des aus seiner Sicht unlösbaren Problems der „Legitimität" güterrechtlicher Teilhabe „der gänzliche Verzicht auf einen gesetzlichen Güterstand." In diese Richtung geht auch der Vorschlag von Rauscher, Reform (Fn. 76), S. 25, der „alternativ wählbare gesetzliche Güterstände“ vorschlägt. Dazu kritisch Mecke, Grundsatzfragen (Fn. 3), S. 923-925. 
gemeine soziale Akzeptanz statt Konsens und zusätzlich mangels indizierter inhaltlicher Richtigkeit eine vom individuellen Willen der Beteiligten unabhängige rechtsethische Begründung.

\section{Legitimation güterrechtlicher Teilhabe in der Geschichte des Ehegüterrechts}

Blickt man zurück auf die Geschichte des Ehegüterrechts, ${ }^{20}$ so erkennt man schon früh eine im Prinzip kommutativer Gerechtigkeit wurzelnde ausdrückliche oder implizite Verknüpfung von güterrechtlicher Teilhabe auf der einen Seite mit einem vom Teilhabeberechtigten zu leistenden wirtschaftlichen Einsatzwert auf der anderen Seite. Wo diese Verknüpfung fehlte, wurde dies auch bereits in früheren Jahrhunderten als ein Mangel an Legitimität für güterrechtliche Teilhabe empfunden. So schreibt im Jahre 1750 der an der Universität Erlangen-Nürnberg lehrende Jurist Carl Adolph von Braun:

„Die Frau [...] verdient nichts, und trägt also zur Errungenschaft nichts bei; und bekommt die Helfte der Errungenschaft dazu; da es aber an ein Bezablen gehet, so ziehet sie den Kopf aus der Schlinge. Was ist dieses anders, als der Frau alle commoda, hingegen dem Manne sine commodo alle incommoda aufbürden?" 21

Die hier insinuierte Verknüpfung von Vermögens- und Haftungsteilhabe, die auch heutigen güterrechtlichen Errungenschaftsgemeinschaften zugrundeliegt, bildet nur ein Beispiel für die im Sinne kommutativer Gerechtigkeit erfolgende Verknüpfung von Teilhabe mit einem ökonomisch relevanten Austauschwert. Mindestens ebenso wichtig war in geschichtlichen Systemen des Ehegüterrechts die im vorstehenden Zitat ebenfalls angeführte conlaboratio beider Ehegatten. Insbesondere im städtischen Handwerk war bereits im Mittelalter die Mitarbeit der Ehefrau im Gewerbe des Ehemannes häufig legitimierender Grund für gesamthänderischen Erwerb von Vermögensgütern während der Ehe, und zwar offenbar selbst dann noch, als die Mitarbeit der Ehefrau im Einzelfall tatsächlich „eher bloß formell“ geworden war. ${ }^{22}$ Neben der Mithaftung oder tatsächlichen Mitarbeit kam auch der Gedanke der von

20 Nicht dem Begriff, aber der Sache nach lässt sich das Güterrecht als die Gesamtheit der Vermögensregelungen für das Verhältnis zwischen Mann und Frau, die deren wirksame Eheschließung zur Voraussetzung haben, bis ins römische Recht zurückverfolgen. Gütergemeinschaften bildeten sich seit dem frühen Mittelalter aus [D.Schwab, „Gleiche Teilhabe am gemeinsam Erarbeiteten“ - Ein Prinzip und seine inneren Spannungen im deutschen Ehevermögensrecht, in: A.-L.Verbeke et al. (Hrsg.), Confronting the Frontiers of Family and Succession Law. Liber Amicorum Walter Pintens, Antwerpen 2012, S. 1241 (1241f.)].

21 C.A.v.Braun, In wieferne die Frau aus dem Heuratsbriefe zur Bezahlung der Schulden des Mannes verbunden ist?, in: Erlangische gelehrte Anzeigen, Erlangen 1750, Nr. XII, S. 129 (133), wieder abgedruckt in: Juristisches Magazin. Erster Band, Jena 1782, S. 273 (281f.). Sofern aber eine solche Regelung ehevertraglich ausdrücklich vereinbart war, sollte auch nach Braun ,über die Sache nicht weiter zu zweifeln“ sein (S. 134 bzw. S. 284), hier ging bereits nach seiner Auffassung der Wille der Beteiligten vor.

22 P.Hradil, Über eheliche Errungenschaftsgemeinschaft auf Grund österreichischer Rechtsquellen des späteren Mittelalters, ZRG GA 36 (1915), S. 459 (467 Fn. 3). 
den Eheleuten gemeinsam getragenen Geschäftsrisiken ${ }^{23}$ sowie der guten Verwaltung des ehelichen Vermögenserwerbs als ein Austauschwert zur Legitimation güterrechtlicher Teilhabe in Betracht. ${ }^{24}$ Umgekehrt ist der gesetzliche Güterstand der „Verwaltung und Nutznießung des Mannes" in der Fassung des BGB von 1896, ${ }^{25}$ der eine Gütertrennung ohne späteren Ausgleich der in der Ehe erworbenen Vorteile vorsah, ein Beleg dafür, dass dort, wo ein legitimierender Zuschreibungsgrund fehlte, auch Gütertrennung gesetzlich vorgesehen werden konnte. Letzteres ist umso bemerkenswerter, als den einschlägigen Vorschriften des BGB in seiner ursprünglichen Fassung ein ausgeprägt institutionelles Eheverständnis zugrunde lag, also die Auffassung der Ehe als ein besonderes Gemeinschaftsverhältnis von Ehemann und Ehefrau, dessen „Wesen“ oder „Substanz“ weder für den Staat noch für die Eheleute selbst verfügbar erscheint. ${ }^{26}$

Auf den ersten Blick mag es überraschen, dass der BGB-Gesetzgeber von 1896, der das Wesen der Ehe in einem patriarchalisch geprägten Gemeinschaftsverhältnis der Eheleute sah, ${ }^{27}$ aus der Masse von ca. zweihundert bis dahin in Deutschland geltenden Güterstandsmodellen ausgerechnet einen Güterstand zum gesetzlichen Güterstand erhob, der Gütertrennung vorsah. Der zeitgenössische Gesetzgeber sah darin aber keineswegs einen inneren Widerspruch. Dies hängt zusammen mit der großen gesellschaftlichen Zäsur in der Geschichte des Ehe- und Familienverständnisses, die der Gesetzgebung von 1896 vorausgegangen war. Bereits im 18. Jahrhundert hatte nämlich der Wandel des Geschlechterverhältnisses von einer Gemeinschaft des „Ganzen Hauses“ zur Kleinfamilie und - ökonomisch ausgedrückt - von der Familie als Produktions- und Konsumgemeinschaft zur Familie als bloßer Konsumgemein-

23 M.Berent, Die Zugewinnstgemeinschaft der Ehegatten, Breslau 1915, S. 77.

24 So heißt es im Landbuch von Appenzell Ausserrhoden (1632), S. 78: „[...] wan es sich begebe, daß zwei Ehemenschen In Ihrer geflissnen Hußhaltung durch den Milten segen Gottes vil hab und gut zusammen leitend, wie dann oftermalen beschicht, vnd billich vnd recht vnß syn bedunkt, daß der Hußfrowen von dem fürschlag [sc. Zugewinn] auch etwaß zu dienen solle“ (zitiert nach E.Huber, System und Geschichte des Schweizerischen Privatrechts. Vierter Band, Basel 1893, S. 460 Fn. 58). Güterrechtliche Teilhabe der Ehefrau bildet nach dem Landbuch die ausdrücklich bestimmte Ausnahme von der Regel und bedurfte daher einer besonderen Legitimation.

25 S $1363-1425$ BGB i.d.F. von 1896.

26 Diese Merkmale sind - bei allen Unterschieden im Übrigen - sämtlichen institutionellen Ehelehren gemeinsam (vgl. dazu nur J.Gernhuber/D.Coester-Waltjen, Familienrecht, 6. Auflage, München 2010, S. 24 Rn. 3f.). Als „Antithese zu solchen institutionellen Ehemodellen“ führen demgegenüber (inter)individuelle Ehelehren, die ihre ideengeschichtlichen Ursprünge zwar bereits im Vertragsdenken der Aufklärung haben, aber gegenüber den spätestens seit Mitte des 19. Jahrhunderts wieder ganz vorherrschenden institutionellen Ehelehren erst seit dem letzten Drittel des 20. Jahrhunderts zunehmend an Boden gewinnen, alle aus der Ehe entstehenden Pflichten auf die übereinstimmenden Willen der Eheleute selbst zurück (Rauscher, Familienrecht, Heidelberg 2001, S. 133 Rn. 231).

27 A.Röthel, Institution und Intimität. Die Ehe, ihre Leitbilder und ihr Recht aus privatrechtlicher Sicht, in: Bucerius Law School, Begegnungen im Recht. Ringvorlesung der Bucerius Law School zu Ehren von Karsten Schmidt anlässlich seines 70. Geburtstages, Tübingen 2011, S. 173 (173f., 176 Fn. 11). 
schaft eingesetzt. ${ }^{28}$ Mit diesem vor allem die städtische Bevölkerung erfassenden Wandel war für eine im 19. Jahrhundert ständig zunehmende Anzahl von Ehen der entscheidende Anknüpfungspunkt und Legitimationsgrund für güterrechtliche Teilhabe der Ehefrau an den vom Ehemann während der Ehezeit erworbenen vermögensrechtlichen Vorteilen - vorerst - entfallen. Es fehlte nämlich ein alternativer Anknüpfungspunkt, der auch nur den Ausgleich ehebedingter Nachteile der Ehefrau hätte begründen können, die auf die Hausfrauen- und Kinderbetreuungstätigkeit beschränkt war. Einen besonders frühen Beleg für diesen einsetzenden Wandel, der in Friedrich Schillers Gedicht „Lied von der Glocke“ (1799) seine klassische literarische Verarbeitung fand, ${ }^{29}$ lieferte ebenfalls der Jurist Carl Adolph von Braun in seiner bereits angeführten Abhandlung von 1750 zur zeitgenössischen Ehevertragspraxis:

„Und endlich hat heutiges Tages [sic!] der Mann zu der Errungenschaft ein weit stärkeres Recht, als die Frau, nach dem die Weibspersonen, unter den Adelichen besonders, wenig oder nichts mehr durch Erwerb beizutragen pflegen. " ${ }^{30}$

Auch jenseits des Adels war der Ehefrau im Übergang von der Sozialform des „Ganzen Hauses " zur bürgerlichen Familie eine berufliche Erwerbsarbeit außer Haus regelmäßig nur im Ausnahmefall erlaubt. ${ }^{31}$ Die Hausfrauen- und Kinderbetreuungsarbeit der Ehefrau galt als unentgeltliche Ehepflicht der Ehefrau ohne wirtschaftlichen Wert. Wegen der damit im Anschluss an das zeitgenössischen Leitbild der bürgerlichen Familie von Gesetzes wegen verordneten Wertlosigkeit der Hausfrauentätigkeit ${ }^{32}$ konnte diese folgerichtig auch weder einen vermögensrechtlichen Vorteil hervorbringen, der güterrechtliche Teilhabe hätte legitimieren können, noch einen vermögensrechtlichen Nachteil verursachen, an den eine Kompensationspflicht des Ehemannes hätte anknüpfen können. Nach dem dahinter stehenden institutionellpatriarchalischen Eheverständnis wurde mithin grundsätzlich die gesamte Vermö-

28 Vgl. dazu nur S.Meder, Grundprobleme und Geschichte der Zugewinngemeinschaft. Wandel der Rollenleitbilder und fortschreitende Individualisierung im Güterrecht, Halle an der Saale 2010, S. 20-24. Vgl. ferner auch schon D.Schwab, Artikel „Familie“, in: O.Brunner/W.Conze/R.Koselleck (Hrsg.), Geschichtliche Grundbegriffe. Historisches Lexikon zur politisch-sozialen Sprache in Deutschland. Band 2: E-G, Stuttgart 1975, S. 253 (272f.), Battes, Sinn (Fn. 4), S. 311; ders., Ehegewinn (Fn. 4), S. 55 m.w.N.

29 Meder, Familienrecht (Fn. 5), S. 132 f.

30 Braun, Frau (Fn. 21), S. 136 bzw. 289.

31 Vgl. die einschlägige Gesetzeslage bis Anfang des 20. Jahrhunderts resümierend A.Duncker, Gleichheit und Ungleichheit in der Ehe. Persönliche Stellung von Frau und Mann im Recht der ehelichen Lebensgemeinschaft 1700-1914, Köln/Weimar/Wien 2003, S. 878f. Das Gleichberechtigungsgesetz gab der Ehefrau im Jahre 1958 zumindest „grundsätzlich das Recht“, auch ohne Zustimmung des Ehemannes „erwerbstätig zu sein“ (BT-Drs. 2/224, S. 29). Die letzten geschlechtsspezifischen gesetzlichen Beschränkungen im Hinblick auf eine außerhäusliche Erwerbstätigkeit der Ehefrau entfielen in Deutschland aber erst mit dem 1. Eherechtsreformgesetz von 1977, denn - so heißt es selbst noch in der Begründung zu diesem Gesetzentwurf wörtlich: „Zwar entspricht die Trennung der Rolle des Verdienenden und der des Haushaltsführenden in der Ehe überwiegend noch der gesellschaftlichen Wirklichkeit [...]. Diese Aufgabenteilung wird jedoch nicht mehr als allein möglich angesehen" (BTDrs. 7/650, S. 97).

32 Anders heute $\mathbb{1 3 6 0}$ BGB. 
genssphäre als eine ehemännliche betrachtet bis hin zu dem Punkt, dass der Ehemann nach dem gesetzlichen Güterstand des BGB von 1896 sogar das von der Ehefrau eingebrachte Vermögen verwaltete und daraus allein die Nutzungen zog. Die nach dem Leitbild der bürgerlichen Ehe idealerweise nicht erwerbstätige Ehefrau war damit güterrechtlich zu einem Neutrum geworden. Eigene vermögensrechtliche Ansprüche der Ehefrau gegenüber dem Ehemann konnten nach diesem Eheverständnis nur aus dem Unterhaltsrecht folgen. Zwar bestanden auch nach Beendigung der Ehe durch Scheidung - allerdings relativiert durch das damals geltende Verschuldensprinzip - unterhaltsrechtliche Ansprüche der schuldlos geschiedenen Ehefrau gegenüber ihrem Ehemann grundsätzlich lebenslang. Diese Ansprüche auf nachehelichen Unterhalt hatten aber sowohl eine andere Funktion als güterrechtliche Teilhabe, da sie nicht auf einen Vorteilsausgleich, sondern auf Fürsorge gerichtet waren, als auch einen anderen Legitimationsgrund. Dieser lag nämlich im Falle der Ausrichtung von Dauer und Maß der Unterhaltspflicht auf die gegenwärtigen und künftigen Bedürfnisse der Ehefrau nicht im Gedanken kommutativer, an einem Austausch- oder Einsatzwert orientierten Gerechtigkeit, sondern in distributiver, nach der individuellen „Würdigkeit“ ${ }^{33}$ bzw. Bedürftigkeit des Empfängers ausgerichteten zuteilenden Gerechtigkeit.

Für die Frage nach der heutigen Legitimation güterrechtlicher Teilhabe lassen sich damit aus der Geschichte des Ehegüterrechts zwei Erkenntnisse gewinnen. Erstens folgen aus einem bestimmten Eheverständnis im Güterrecht keine zwingenden Folgerungen für eine Antwort auf die Frage, ob das Güterrecht auf Gütertrennung oder aber auf irgendeiner Form partieller oder vollständiger Gütergemeinschaft beruhen sollte. ${ }^{34}$ Gütertrennung kann mit einem institutionellen Eheverständnis ebenso vereinbar sein wie umgekehrt Gütergemeinschaft mit einem (inter-)individuellen Eheverständnis, ${ }^{35}$ das die Ehe lediglich als einen offenen Rahmen versteht, den die Ehegatten in den Grenzen, die durch zwingende familienrechtliche Vorschriften etwa im Unterhaltsrecht gesetzt sind, ohne Rekurs auf Tradition und vorgegebene Kollektivwerte ausschließlich selbst füllen. ${ }^{36}$ Unmittelbare Zusammenhänge zwischen einem institutionell-patriarchalischen Eheverständnis und den vermögensrechtlichen Be-

33 Vgl. zu diesem leitenden Gesichtspunkt distributiver Gerechtigkeit H.Henkel, Einführung in die Rechtsphilosophie, München 1977, S. 403f., 408. Traditionell findet das Modell distributiver Gerechtigkeit zwar auf Über-/Unterordnungsverhältnisse Anwendung, wie sie insbesondere zwischen dem Staat und dem Einzelnen bestehen. Bei den Schutz- und Unterstützungsrechten kommt aber das Prinzip distributiver Gerechtigkeit auch in familienrechtlichen Konstellationen etwa zwischen Eltern und Kind (aaO, S. 409) oder - wie im vorliegenden Fall - in der nach institutionell-patriarchalischem Eheverständnis bestehenden Schutzpflicht des Ehemannes gegenüber seiner zum Gehorsam verpflichteten Ehefrau in Betracht.

34 So zu Recht schon J.Gernhuber/D.Coester-Waltien, Familienrecht (Fn. 26), S. 351 Rn. 12-14.

35 Nach J.Gernhuber/D.Coester-Waltjen, Familienrecht (Fn. 26), S. 351 Rn. 12-14 tendiert ein institutionelles Eheverständnis zwar zum System der Gütergemeinschaft, es ist aber auch in Verbindung mit einem System der Gütertrennung denkbar.

36 J.Gernhuber/D.Coester-Waltien, Familienrecht (Fn. 26), S. $24 \mathrm{f}$. 
ziehungen der Eheleute bestehen lediglich im Hinblick auf das geschlechtsspezifisch geregelte gesetzliche Verwaltungsrecht des Ehemannes sowie Verfügungsbeschränkungen der Ehefrau, wie sie der BGB-Gesetzgeber von 1896 in der Tat vorsah. ${ }^{37}$ Diese Frage der geschlechtsspezifisch eingeschränkten Verfügungsfreiheit der Ehefrau bildete folgerichtig auch den Hauptkritikpunkt der frühen Frauenrechtsrechtsbewegung am gesetzlichen Güterstand des BGB in der im Jahre 1900 in Kraft getretenen Fassung von 1896. Wenn daher die Vertreterinnen der Frauenrechtsbewegung, deren Formierung nach der Veröffentlichung des Ersten Entwurfs zum BGB (1888) einen entscheidenden Schub erfuhr, ${ }^{38}$ zunächst fast einhellig die Einführung der Gütertrennung als gesetzlichen Güterstand forderten, dann zielte diese Forderung keineswegs auf den Ausschluss der Frauen von dem während der Ehe erzielten Vermögenserwerb des Ehemannes. Gütertrennung erschien den Frauen damals vielmehr als das einzige probate Mittel, um sich der geschlechtsspezifischen Verfügungsbeschränkungen zu entledigen, die das - gleichwohl im Jahre 1900 Gesetz gewordene - patriarchalische Ernährermodell eines Güterstandes der Gütertrennung verbunden mit einer ehemännlichen Verwaltung und Nutznießung des Frauenvermögens vorsah. ${ }^{39}$

Eine zweite aus der Geschichte von Ehe und Ehegüterrecht zu gewinnende Erkenntnis besteht darin, dass eine Beschränkung auf juristische Konstruktionen güterrechtlicher Vergemeinschaftung für einen Vergleich geschichtlicher und heute geltender Güterrechtsmodelle nicht ausreicht. Es würde den Blick dafür verstellen, dass Befürworter güterrechtlicher Teilhabe seit der großen Zäsur, die der Wandel der Familie von einer „Produktions- und Konsumgemeinschaft“ des „Ganzen Hauses“ zum Regelfall einer bloßen Konsumgemeinschaft der heutigen Kleinfamilie darstellt, vor einem ganz neuen Legitimationsproblem standen. Dieses mit dem familiengeschichtlichen Wandel verbundene Legitimationsproblem wurde Mitte der fünfziger Jahre weder vom Gesetzgeber des Gleichberechtigungsgesetzes klar gesehen noch von den Vertretern der zeitgenössischen Wissenschaft, die vorwiegend nur über die richtige Form der Teilhabe diskutierten. So ging der Gesetzgeber des Gleichberechtigungsgesetzes davon aus, dass Haushaltsführung in der Ehe nicht anders zu behandeln sei als Mitarbeit im Erwerbsgeschäft des Ehegatten. So heißt es 1954 im zweiten Regierungsentwurf zum Gleichberechtigungsgesetz:

37 Vgl. $\$ \mathbb{S} 1363,1365,1373 f ., 1376,1380,1383,1395-1400,1403 f$. BGB i.d.F. von 1896 sowie zur zeitgenössischen Kritik S.Meder, Eigenverantwortung und Solidarität im deutschen Ehegüterrecht: Reformforderungen der bürgerlichen Frauenbewegung und künftige Ausgestaltung des Zugewinnausgleichs, in: BMFSFJ (Hrsg.), Dokumentation der Tagung „Rollenleitbilder und -realitäten in Europa: Rechtliche, ökonomische und kulturelle Dimensionen“, Baden-Baden 2009, S. 142 (143f.).

Meder, Familienrecht (Fn. 5), S. 193, $211 \mathrm{f}$.

39

Meder, Individualisierung (Fn. 11), S. $156 \mathrm{f}$. 
„Der vom Entwurf vorgesehene Güterstand geht [...] von der Erwägung aus, daß der Mann den Gewinn, den er in der Ehe erzielt, entweder unmittelbar der Mitarbeit der Frau im Geschäft oder mittelbar der Arbeit der Frau im Hause mitverdankt. “40

Für beide Fälle der „Mitarbeit“ sollte die Zugewinngemeinschaft eine angemessene güterrechtliche Teilhabe gewähren. Dies erstaunt angesichts der Tatsache, dass die Verbreitung von Mitarbeit der Ehefrau im Erwerbsgeschäft des Ehegatten zu diesem Zeitpunkt bereits ihren Höhepunkt überschritten hatte und zudem auch gar nicht dem Familienbild des damaligen Gesetzgebers entsprach. Ausdrücklich stellen die Verfasser des zweiten Gesetzgebungsentwurfs fest:

„Es gehört zu den Funktionen des Mannes, daß er grundsätzlich der Erhalter und der Ernährer der Familie ist, während die Fran es als ihre vornehmste Aufgabe ansehen muß, das Herz der Familie zu sein." 41

Damit wurde eine Mitarbeit der Ehefrau im Erwerbsgeschäft des Ehemannes zwar nicht ausgeschlossen, aber zur Ausnahme vom Regelfall der idealtypischen Durchschnittsehe erklärt - eine Ausnahme, die nun das neu einzuführende Prinzip güterrechtlicher Vermögensteilhabe der Ehefrau zumindest mittragen sollte. ${ }^{42}$

In besonderer Weise begründungsbedürftig gewesen wäre jedoch vor allem die Gleichsetzung von im Einzelfall unvermeidbarer erwerbsmäßiger Mitarbeit der Ehefrau mit der bis zu dieser Zeit vermögensrechtlich vollkommen unbeachtlichen Haushaltsführung. Der Gesetzgeber des Gleichberechtigungsgesetzes, der nach Inkrafttreten des Grundgesetzes durch Art. 3 Abs. 2 GG gezwungen war, die gesetzliche Gleichberechtigung von Mann und Frau auch im Ehe- und Familienrecht einzuführen, hat zwar im Rahmen der Regelung der gemeinsamen Pflichten beider Eheleute zur Leistung des ehelichen Unterhalts die berufliche Erwerbsarbeit des Ehemannes und die Haushaltsführung der Ehefrau als „gleichwertig“ bezeichnet und damit zumindest mittelbar einen ökonomischen Wert der Haushaltsführung anerkannt. ${ }^{43}$ Aus den Gesetzesmaterialien ergibt sich aber auch, dass es weniger die „Mitarbeit“ der Ehefrau war, die den Zugewinnausgleich legitimieren sollte, als „vor allem“ das Be-

40 BT-Drs. 2/224, S. 31.

41 BT-Drs. 2/224, S. 29.

42 Nach der Begründung zum zweiten Gesetzesentwurf des Gleichberechtigungsgesetzes ist „die Frau [...] berechtigt und verpflichtet, das gemeinschaftliche Hauswesen zu leiten“, zu „Arbeiten im Hauswesen und im Geschäft des Mannes“ sei die Ehefrau nach der „natürlichen Ordnung“ hingegen nur noch „verpflichtet, soweit eine solche Tätigkeit nach den Verhältnissen, in denen die Ehegatten leben, üblich ist" (BT-Drs. 2/224, S. 29).

43 BT-Drs. 2/224, S. 30: „Die Leistungen von Mann und Frau sind einander gleichwertig.“ Diese normative Festlegung im Hinblick auf die ehelichen Unterhaltspflichten von Mann und Frau gestattete allerdings vor allem das Festhalten an ,unserer überlieferten Auffassung von der Ehe, daß grundsätzlich der Mann erwerbstätig ist und die Frau den Haushalt führt“ (aaO). 
streben, den haushaltsführenden „Ehegatten bei Auflösung der Ehe sicherzustellen “, ${ }^{44}$ also eine Aufgabe, die nach dem damals noch vorherrschenden Verständnis der Ehe als Schicksalsgemeinschaft bisher dem Recht des nachehelichen Unterhalts zugekommen war und auch weiterhin zukam. Schon die Diskussion um eine Reform des gesetzlichen Güterstandes in der Weimarer Republik war durch den Streit darüber geprägt gewesen, ob ein güterrechtlicher Ausgleich zugunsten der Ehefrau an deren Tätigkeit oder aber an dem Gedanken einer über die Ehe hinaus fortwirkenden Fürsorge für die Ehefrau anknüpfen sollte. ${ }^{45}$ Die Entwurfsbegründung aus den fünfziger Jahren enthält beide Aspekte und zeugt damit von der Unentschiedenheit des Gesetzgebers im Hinblick auf die Legitimation güterrechtlicher Teilhabe.

\section{Drei Begründungsmodelle zur heutigen Legitimation des Umfangs güterrechtlicher Teilhabe}

Ordnet man die Argumente, die in der heutigen Debatte um die Legitimation güterrechtlicher Teilhabe angeführt werden, einzelnen Begründungsmodellen zu, so lassen sich mindestens drei prinzipiell verschiedene Denkmodelle erkennen, deren unterschiedlicher Begründungsansatz nicht nur von theoretischem Interesse ist, sondern auch praktisch zu unterschiedlichen Ergebnissen führt. Am weitesten reicht güterrechtliche Teilhabe nach einem Begründungsmodell, das weder an einer vermögensrechtlich relevanten Leistung des Ausgleichsberechtigten noch an einer entsprechenden Einbuße des Ausgleichsverpflichteten anknüpft, sondern lediglich an der Tatsache des Bestehens einer Gemeinschaft der Eheleute bzw. gleichgeschlechtlichen Lebenspartner (dazu I.). Enger gefasst ist güterrechtliche Teilhabe hingegen nach dem hergebrachten, verschiedenen Arten unterfallenden Grundmodell, das güterrechtliche Teilhabe mit einer vermögensrechtlich relevanten unmittelbaren oder mittelbaren Leistung des Ausgleichsberechtigten legitimiert (dazu II.). Beide vorgenannten Begründungsmodelle haben gemeinsam, dass die durch sie begründete Teilhabe auf die Gesamtheit vermögensrechtlicher Vorteile als Gegenstand güterrechtlicher Vergemeinschaftung zielt. Davon unterscheiden sich diese Begründungsmodelle von solchen, die güterrechtliche Teilhabe ausschließlich auf den Ausgleich ehebedingter Vermögensnachteile des Ausgleichsberechtigten beschränken wollen (dazu III.).

44 BT-Drs. 2/224, S. 44. Ausdrücklich weist die Begründung zum Gesetzesentwurf darauf hin, dass der künftige „Anspruch eines Ehegatten auf den Ausgleich des Zugewinns [...] kein Lohn für geleistete Arbeit" sei (aaO), sondern vielmehr den nach dem „Wesen der Ehe“ ungerechten Zustand verhindern solle, dass der erwerbstätige Ehemann nach Auflösung der Ehe materiell besser abgesichert sei als die geschiedene Ehefrau mit einem „in der Praxis oft nicht durchsetzbaren Unterhaltsanspruch“ (aaO, S. 37). Abgesehen davon, dass ein schuldrechtlicher Anspruch auf Zugewinnausgleich nicht anders als ein Unterhaltsanspruch „,in der Praxis“ durchgesetzt werden muss, wurde güterrechtliche Teilhabe aus dieser Sicht zu einer Rückversicherung des nachehelichen Unterhalts.

45 M.Lieb, Die Ehegattenmitarbeit im Spannungsverhältnis zwischen Rechtsgeschäft, Bereicherungsausgleich und gesetzlichem Güterstand. Zugleich ein Beitrag zur Rechtsfortbildung im Familienrecht, Tübingen 1970, S. 176. 


\section{Begründungsmodell güterrechtlicher Teilhabe aufgrund des Bestehens einer Solidargemeinschaft}

$\mathrm{Zu}$ dem Begründungsmodell, das unmittelbar an das Vorhandensein einer vermögensrechtlichen Solidargemeinschaft anknüpft, gehört die im Jahre 1957 vom bundesdeutschen Gesetzgeber des Gleichberechtigungsgesetzes angeführte Legitimation güterrechtlicher Teilhabe mit dem Gedanken der Ehe als einer Schicksalsgemeinschaft. ${ }^{46}$ Danach besteht in der Ehe auch in vermögensrechtlicher Hinsicht eine Gemeinschaft „im Guten wie im Schlechten“, mithin ein wechselseitiges Teilhaberecht an grundsätzlich allen während der Ehe eingetretenen Vermögenszuwächsen. Das Recht auf gleiche Teilhabe an dem während des Güterstandes entstandenen Wertzuwachs des Nettovermögens kann im Sinne des Prinzips kommutativer Gerechtigkeit als ein Ausgleich für die Pflicht gelten, solidarisch alle Vermögensrisiken und sonstigen zumindest nach Begründung des Güterstandes entstandenen Lasten zu tragen, wie auch immer sie verursacht sein mögen.

In der heutigen Familienrechtswissenschaft wird die Ehe aber nur noch vereinzelt als Schicksalsgemeinschaft bezeichnet. ${ }^{47}$ Das gilt erst recht für die eingetragene Lebenspartnerschaft, für die sich diese Vorstellung vom Beginn ihres Bestehens nicht eingebürgert hat. Aber auch der Topos vom „Wesen der Ehe als Schicksalsgemeinschaft" erscheint unter den Bedingungen fortschreitender Individualisierung nicht nur mit Blick auf steigende Scheidungszahlen als tragende Begründung für güterrechtliche Teilhabe überholt, ${ }^{48} \mathrm{da}$ sich in den letzten fünfzig Jahren die Einstellung gegenüber der Ehe grundsätzlich verändert hat. Sie hat heute ihren noch in den 1950er Jahren weithin unbestrittenen Charakter als prinzipiell lebenslange Schicksalsgemeinschaft inzwischen weitgehend verloren. Das hat nicht nur Folgen für die Akzeptanz von Grund und Dauer nachehelicher Unterhaltspflichten. Auch im Güterrecht stößt insbesondere die Legitimation eines noch nach der Ehe erfolgenden Vermögensausgleichs ${ }^{49}$ mit Hinweis auf die sich aus der Schicksalsgemeinschaft er-

46 Vgl. insoweit nur die Begründung des zweiten Regierungsentwurfs zum Gleichberechtigungsgesetz (BT-Drs. 2/224, S. 44).

47 So etwa von L.Kähler, Nachwirkende Verantwortung statt Nachteilsausgleich - zur Rechtfertigung des Scheidungsunterhalts, AcP 211 (2011), S. 274. Vgl. auch H.Kögler, Das defizitäre Anfangsvermögen beim Zugewinnausgleich, Frankfurt a.M. 2000, S. 72, dem es im Anschluss an die Rechtsprechung des BGH ,nicht ungerechtfertigt erscheint, die eheliche Gemeinschaft als ,Schicksals- und Risikogemeinschaft" zu bezeichnen." In direktem Anschluss an entsprechende Äußerungen aus der Rechtswissenschaft der fünfziger Jahre stellt ferner Urbach, Zugewinngemeinschaft (Fn. 4), S. 47 fest, dass „die Ehe als dauerhafte Lebens- und Schicksalsgemeinschaft darauf ausgerichtet sei, das Leben von Mann und Frau in naturgegebener Weise zu verbinden “, und leitet daraus die weitreichende Folgerung ab, dass der gegenwärtig geltende gesetzliche Güterstand des BGB einer „der Ehe ureigenen Grundidee von Bindung und Vergemeinschaftung " widerspreche.

48 Meder, Grundprobleme (Fn. 28), S. 41, 65f.

49 Vgl. dazu grundlegend für das Recht des nachehelichen Unterhalts B.Metz, Rechtsethische Prinzipien des nachehelichen Unterhalts. Eine Kritik an der nachwirkenden ehelichen Solidarität, Frankfurt a.M. 2005; G.Brudermüller, Geschieden und doch gebunden? Ehegattenunterhalt zwischen Recht und Moral, München 2008; Kähler, Verantwortung (Fn. ), S. 262-286. 
gebenden nachehelichen Pflichten nicht mehr auf weithin geteilte Zustimmung. So haben in jüngerer Zeit in Deutschland durchgeführte sozialempirische Untersuchungen ergeben, dass nach dem Scheitern einer Ehe nur noch eine sehr geringe Bereitschaft besteht, „für die Expartnerin/den Expartner eine gewisse Verantwortung zu tragen, z.B. weil sie/er während der Partnerschaft verschiedentlich beruflich zurückgesteckt hat" oder auch schlicht bedürftig ist. ${ }^{50}$

Nicht in der Begründung, wohl aber im Ergebnis nahe kommt diesem traditionellen Legitimationsmodell güterrechtlicher Teilhabe als der vermögensrechtlichen Seite einer ehelichen Schicksalsgemeinschaft eine erst seit einigen Jahren vertretene Konzeption, die an der heute vorherrschenden ökonomischen Funktion der Ehe im Verhältnis der Eheleute zueinander anknüpft. Dieser vor zwanzig Jahren zuerst von Robert Battes vertretenen Legitimation güterrechtlicher Teilhabe liegt die Beobachtung zugrunde, dass die eheliche Lebensgemeinschaft in ökonomischer Hinsicht „überwiegend durch gemeinsamen Konsum und nicht mehr durch gemeinsamen Broterwerb (wie in der Agrargesellschaft) gekennzeichnet" sei. ${ }^{51}$ Teilhabe sei damit kein Ausgleich für eine selbst im weitesten Sinne verstandene Leistung des Berechtigten. Vielmehr sei Teilhabe Ausgleich für eine ungleichmäßige Verteilung konsumierbaren Vermögens. Das Recht auf Teilhabe knüpft hier also maßgeblich an den Gedanken einer gleichmäßigen Berechtigung zum Konsum des während der Ehe entstandenen Vermögens an, ${ }^{52}$ mag das Vermögen nun auf wirtschaftlichem Erwerb oder auf Glückszufällen beruhen. ${ }^{53}$

Auf den ersten Blick scheint dieses Modell am konsequentesten den beschriebenen Wandel der Familie von einer „Produktions- und Konsumgemeinschaft“ zu einer „bloße[n] Konsumgemeinschaft " $\mathrm{f}^{4}$ auch in güterrechtlicher Hinsicht umzusetzen. In dieser scheinbaren Stärke der Realitätsnähe und Einfachheit der Durchführung liegt aber auch seine Schwäche. Allein die soziale Tatsache einer „Konsumgemeinschaft“ enthält noch keinen Legitimationsgrund, keine iusta causa für güterrechtliche Teilhabe. Dies sieht auch Battes, wenn er die Teilhabe normativ mit einer ehelichen Grundpflicht zu begründen versucht, nämlich mit der Pflicht der Eheleute zum ge-

50 BMFSFJ, Sociovision (Fn. 8), S. 12.

51 Battes, Sinn (Fn. 4), S. 311, 314.

52 Battes, Sinn (Fn. 4), S. 311, 321. Wie Battes sieht auch Kögler, Anfangsvermögen (Fn. 47), S. 53 die „Rechtfertigung des Zugewinnausgleichs [...] ausschließlich“ in „der ehelichen Lebensgemeinschaft als solcher. Diese ist nur dann in vollem Umfange verwirklicht, wenn bei Beendigung des Güterstandes eine gleichberechtigte Beteiligung am erwirtschafteten Vermögen gesichert ist.“.

53 Die Tatsache, dass Battes, Ehegewinn (Fn. 4), S. 57f. gleichwohl beispielsweise Schmerzensgeld im Unterschied zu Gewinnen aus Glücksspielen nicht als Bestandteil der Konsumgemeinschaft beider Eheleute betrachtet, obwohl durchaus auch ein „Ausgleich immaterieller Nachteile zusätzliche Konsummöglichkeiten eröffnen soll“, ist ebenfalls nach Battes nicht mehr aus dem „Grundgedanken des Zugewinnausgleichs“, sondern nur aus der besonderen ratio legis der jeweils anspruchsgewährenden Vorschrift abzuleiten, also im Falle von Schmerzensgeldansprüchen aus dem Zweck einer ausschließlich für den verletzten Ehepartner bestimmten persönlichen Genugtuung.

54 Battes, Sinn (Fn. 4), S. $323 \mathrm{f}$. 
meinsamen Konsum des gesamten „Ehegewinns“. Aus dieser Pflicht leitet er für die Zeit nach Beendigung des Güterstandes die Folgepflicht ab, „grundsätzlich schlechthin alles zu verteilen, was hätte ausgegeben werden können, aber [noch] nicht ausgegeben worden ist. " 55 Eine derartige eheliche Grundpflicht zum gemeinsamen Konsum bestände aber allenfalls dann, wenn der ökonomische Zweck der Ehe bzw. eingetragenen Lebenspartnerschaft tatsächlich im gemeinsamen Konsum der während des Güterstandes erlangten Vermögensvorteile bestünde. Das ist aber vor allem für den in Deutschland geltenden gesetzlichen Güterstand, der während der Dauer der Ehe bzw. Lebenspartnerschaft gerade auf Gütertrennung und damit - lediglich eingeschränkt durch wechselseitige Pflichten zum ehelichen bzw. lebenspartnerschaftlichen Unterhalt - auf dem von Gesetzes wegen verbrieften Recht auf einseitigem Konsum beruht, mehr als fraglich. ${ }^{56}$ Battes selbst räumt ein, dass in denjenigen Fällen, in denen nicht nur rechtlich, sondern auch faktisch keine Konsumgemeinschaft vorliege, weil der eine „Ehegatte am Konsum des andern nicht teil[nimmt] und [...] dessen Ausgaben auch nicht den Kindern zugute " kommen, der Gedanke der Konsumgemeinschaft güterrechtliche Teilhabe nicht mehr legitimieren könne. ${ }^{57}$

\section{Begründungsmodell güterrechtlicher Teilhabe aufgrund der Mitverursachung von Vermögensvorteilen}

Mehrheitlich wird in heutigen Begründungsansätzen gemeinsamer Konsum weiterhin nicht als Grund, sondern nur als Ausdruck güterrechtlicher Teilhabe angesehen. Ihren Grund und ihre Begrenzung findet Teilhabe danach im Gedanken der Mitverursachung von Vermögensvorteilen, wobei Art und Maß der geforderten Mitverursachung im Einzelnen sehr unterschiedlich sein können. Mitverursachung kann sich sowohl auf den Erwerb des anderen Ehegatten bzw. Lebenspartners selbst als auch auf die - sparsame - Verwaltung des Erworbenen beziehen, sie kann unmittelbar oder auch nur mittelbar auf einer Leistung des Teilhabeberechtigten beruhen, außerdem kann sie auf den gesamten oder auch nur auf einen - zum Beispiel den beruflichen - Teil des vom anderen Ehegatten erworbenen Vermögens zielen. ${ }^{58}$

Unmittelbare Mitverursachung des Vermögenserwerbs des anderen Ehegatten wird vor allem in den Fällen unentgeltlicher Mitarbeit im Erwerbsgeschäft des anderen anzunehmen sein. Abgesehen davon, dass die Mehrheit der heutigen Ehen und Le-

55 Battes, Ehegewinn (Fn. 4), S. 56.

56 Battes, Ehegewinn (Fn. 4), S. 56 folgert allerdings gerade aus dem BGB-Zugewinnausgleich eine derartige Pflicht, ,auch wenn dies den Verfassern des Gesetzes nicht bewußt gewesen sein mag“.

57 Battes, Sinn (Fn. 4), S. 316, 324 („Verteilungsschema versagt“).

58 Vgl. dazu nur Gernhuber/Coester-Waltjen, Familienrecht (Fn. 26), S. 368 Rn. 3: Je nachdem, ob der Ausgleich deswegen erfolgen soll, weil einer der Ehegatten „dem Partner den vollen Einsatz seiner Arbeitskraft im Berufsleben ermöglichte“, oder aber, „weil der Ehegatte mit dem geringeren Zugewinn den größeren Erwerb des Partners jedenfalls mitverursacht habe“, wäre „die sachrichtige Teilungsgröße der Zugewinn aus Erwerbstätigkeit“ des anderen oder aber „aller Erwerb beider Ehegatten, der überhaupt sinnvoll mit dem Gedanken der Mitverursachung verbunden werden kann“. 
benspartnerschaften eben nicht mehr eine Produktionsgemeinschaft darstellt, ist aber nach höchstrichterlicher Rechtsprechung gerade die unentgeltliche Mitarbeit im Erwerbsgeschäft des anderen Ehegatten diejenige Form der Mitverursachung, die im Unterschied zur Intention des Gesetzgebers des Gleichberechtigungsgesetzes von 1957 durch den Zugewinnausgleich nicht adäquat erfasst werden kann. ${ }^{59}$ Dies hat in den letzten fünfzig Jahren zu der inzwischen nur noch schwer überschaubaren Entwicklung eines sogenannten richterrechtlichen Nebengüterrechts geführt. ${ }^{60}$ Jenseits der unengeltlichen Mitarbeit im Erwerbsgeschäft des anderen kämen noch Haushaltsführung und Kinderbetreuungsarbeit in Betracht, deren ökonomischer Wert zwar spätestens seit Erlass des Gleichberechtigungsgesetzes im Grundsatz unbestritten ist. Bestritten ist aber die vom ökonomischen Wert der Tätigkeit ${ }^{61} \mathrm{zu}$ unterscheidende „ökonomische Auswirkung “ der Haushaltsführung im Vermögen des anderen, ${ }^{62}$ die allein Grundlage für eine Teilhabe am Vermögenszuwachs aufgrund unmittelbarer Mitverursachung sein könnte. In der Regel wird Haushaltsführung daher nur als mittelbare Mitverursachung der Vermögenszuwächse im Vermögen des anderen betrachtet, da sie mutmaßlich eine ausgedehntere, zum zusätzlichen Vermögenszuwachs führende Erwerbstätigkeit des anderen ermögliche und damit mittelbar - auch den darauf beruhenden höheren Zuwachs in dessen Vermögen verursache.

Gemeinsam ist den meisten Theorien, die die Mitverursachung zum Anknüpfungspunkt für die Vermögensteilhabe machen, aber der Umstand, dass der Gedanke einer bestimmten Form der Mitverursachung von Vermögenszuwächsen beim anderen Partner zwar die rechtliche causa bildet, nicht aber auch die im Einzelfall nachzuweisende tatsächliche Voraussetzung für güterrechtliche Teilhabe. Mitverursachung wird also danach nicht im Sinne eines konkreten ökonomischen Kausalzusammenhangs, sondern im Sinne einer typisierenden normativen Zuschreibung aufgefasst.

59 Vgl. Lieb, Ehegattenmitarbeit (Fn. 45), S. 156, 162.

60 M.Schlimm, Die Ehegatteninnengesellschaft im außergüterrechtlichen Vermögensausgleich. Rechtsprechungsentwicklung, offene Frage und Folgeprobleme, Hamburg 2010; T.Herr, Kritik der konkludenten Ehegatteninnengesellschaft. Der Ausgleich ehelicher Mitarbeit als ehebezogene Wertschöpfung im Rahmen richterlicher Inhalts- und Ausübungskontrolle von Eheverträgen, Bonn 2008; ders., Nebengüterrecht. Ausgleichsansprüche bei Gütertrennung und gestörtem Zugewinnausgleich, München 2013.

61 Den ökonomischen Wert der Hausfrauentätigkeit thematisierten erstmals Vertreterinnen der frühen Frauenrechtsbewegung wie Emilie Kempin (1897) sowie etwas später Käthe Schirrmacher (1905) und Marianne Weber (1907). Kritisch gegenüber Forderungen, die damals „selbst bis tief in die Reihen der sog. gemäßigten Frauenvereine hinein “ verbreitet waren, meinte P.Oertmann, Gehaltsansprüche der Ehefrau, Deutsche Juristen-Zeitung 1911, Sp. 124 (124, 129), dass aus der „ordentliche[n] Haushaltsführung “ zwar keine „Gehaltsansprüche der Ehefrau abzuleiten seien“, wohl aber auf güterrechtlichem Wege ein Anteil der Ehefrau am Vermögen des Ehemannes „nach Maßgabe des ökonomischen Enderfolges der ehelichen Lebensgemeinschaft“. Eben dies forderten auf den Deutschen Juristentagen 1924 und 1931 auch Marie Munk bzw. Else Lüders [vgl. dazu Meder, Grundprobleme (Fn. 28), S. 24f.; ders., Individualisierung (Fn. 11), S. 148f.].

62 Sie wird generell bestritten von Lieb, Ehegattenmitarbeit (Fn. 45), S. 181: „Die eheliche Lebensgemeinschaft ist ökonomisch neutral“". 
Eben diese gerade auch dem deutschen gesetzlichen Güterstand zugrundeliegende Typisierung ${ }^{63}$ wird seit einigen Jahren zunehmend kritisch gesehen. ${ }^{64}$ Auch diejenigen, die an ihr grundsätzlich festhalten wollen, betrachten es für eine typisierend normative Zuschreibung zunehmend nicht mehr als ausreichend, dass der Vermögenszuwachs lediglich während der Dauer des Güterstandes erfolgte, also im Falle der Ehe nur ehezeitlich und nicht auch ehebedingt war.

Eine konsequente Umwandlung des bisher normativ zu verstehenden Begriffs der Mitverursachung in einen Begriff der Mitverursachung im Sinne faktischer Kausalzusammenhänge würde güterrechtliche Teilhabe auf im konkreten Einzelfall nachweislich ehe- bzw. lebenspartnerschaftsbedingte Vermögensvorteile beschränken. Theoretisch würde durch eine genaue güterrechtliche Feststellung der vermögensmehrenden Leistung jedes Partners der Gedanke einer Individualisierung des güterrechtlichen Verhältnisses zwischen den Partnern konsequent zu Ende gedacht. Der Preis dafür wäre allerdings, dass nicht nur eine fiktive Erwerbsbiographie des ausgleichsverpflichteten Partners gebildet werden müsste, sondern auch ein anschließender Vergleich des tatsächlichen mit dem hypothetischen Vermögenserwerb „ohne die Ehe zum Zeitpunkt der Scheidung “. ${ }^{65}$ Dieser Preis wäre jedoch für die Rechtspraxis mit Blick auf die Praktikabilität und Rechtssicherheit wohl zu hoch. Zwar könnte man einwenden, dass im Recht des nachehelichen Unterhalts bereits de lege lata gemäß $\$ 1578$ b BGB die Bildung einer fiktiven Erwerbsbiographie des Unterhaltsberechtigten erforderlich werden kann zur Feststellung tatsächlich erlittener ehebedingter Nachteile im Rahmen der Herabsetzung bzw. zeitlichen Begrenzung des nachehelichen Unterhalts. ${ }^{66}$ Hier kann aber wenigstens die Bildung einer fiktiven Erwerbsbiographie des Unterhaltsberechtigten an die Entwicklung der realen Ausbildungs- und Erwerbsbiographie bis zur Eheschließung anknüpfen. Damit kann

63 Dagegen sieht der 1983 in Griechenland eingeführte gesetzliche Güterstand der Zugewinngemeinschaft eine Mischform zwischen Typisierung und tatsächlichem Nachweis vor. Derjenige, der nach Beendigung des Güterstandes mehr als ein Drittel des Zugewinns seines bisherigen Ehepartners fordert, muss vor Gericht beweisen, dass er zu dem entsprechenden Zuwachs im Vermögen des anderen auch tatsächlich selbst beigetragen hat [I.Vlassopoulou, Rechtsprechung zum Zugewinnausgleich nach griechischem Recht, in: D.Henrich/D.Schwab, Eheliche Gemeinschaft, Partnerschaft und Vermögen im europäischen Vergleich, Bielefeld 1999, S. 115 (122); R.Battes, Zur Vermögensauseinandersetzung im Fall der Ehescheidung. Rechtsvergleichende Skizze mit Ausblicken auf das Gesellschaftsrecht, in: T.Baums/J.Wertenbruch (Hrsg.), Festschrift für Ulrich Huber zum siebzigsten Geburtstag, Tübingen 2006, S. $99(102)]$.

64 D.Schwab, Der Vermögensausgleich bei Trennung und Scheidung - ein unbeackertes Reformfeld des Gesetzgebers?, in: Deutscher Familiengerichtstag e.V. (Hrsg.), Elfter Deutscher Familiengerichtstag, Bielefeld 1996, S. 33 (38); I.Schwenzer, Grundlinien eines modernen Familienrechts aus vergleichender Sicht, RabelsZ 2007, S. 705 (718).

65 Vgl. Brudermüller, Geschieden (Fn. 49), S. 175: „Bei der Beurteilung, ob ein ehebedingter Vorteil vorliegt, ist es - als Kehrseite zu den ehebedingten Nachteilen konsequent - entscheidend, welche berufliche Ebene dieser Ehepartner ohne die Ehe zum Zeitpunkt der Scheidung erreicht hätte; es kommt nicht darauf an, wie die Aufgabenverteilung in der jeweiligen Ehe war.".

66 So in der Tat Kähler, Verantwortung (Fn. 47), S. 272, für den ehebedingte Nachteile als genereller Maßstab des Scheidungsunterhalts mangels praktikabler Feststellungsmöglichkeiten ausscheiden. 
man versuchen, diese reale Biographie unter Absehung von der eingegangenen Ehe bzw. eingetragenen Lebenspartnerschaft fiktiv fortzuschreiben, um durch einen Vergleich mit der tatsächlichen Erwerbsbiographie während der Dauer des Güterstandes die ehe- bzw. partnerschaftsbedingten Vermögenseinbußen für den einzelnen Güterstandsbeteiligten ziffernmäßig festzustellen. Eine entsprechende Feststellung ehebedingt erlangter Vermögensvorteile ist hingegen noch ungleich schwieriger, weil sich allein aus der Ausbildungs- und Erwerbsbiographie bis zur Begründung des Güterstandes kaum zuverlässig ableiten lässt, welche Vermögensvorteile ein Güterstandsbeteiligter in einer unter Umständen über viele Jahrzehnte reichende fiktiven Parallelbiographie ohne die in Rede stehende Ehe bzw. Lebenspartnerschaft erlangt haben würde.

Mehr Aussicht auf Verwirklichung hat hingegen, was vor einigen Jahren bereits der 16. Deutsche Familiengerichtstag zur Eingrenzung des ehezeitlichen Zugewinns auf den ehebedingten Vermögenszuwachs gefordert hat. Danach soll durch eine in \$ 1374 Abs. 2 BGB neu einzufügende Generalklausel zumindest derjenige während der Dauer des Güterstandes erfolgte Vermögenserwerb aus der güterrechtlichen Teilhabe ausgeschlossen werden, der „nach seiner Zweckbestimmung in keiner Beziehung zur ehelichen Lebens- und Wirtschaftsgemeinschaft steht “ ${ }^{67}$ Wenn schon eine positive Feststellung des ehebedingten Vermögenserwerbs nicht praktikabel ist, dann sollte in der Tat wenigstens konsequent derjenige Vermögenserwerb, der im Einzelfall offensichtlich oder im Regelfall „typischerweise“ 68 nicht ehebedingt ist, aus der Vermögensteilhabe ausgeschlossen werden. Das sollte in Deutschland nicht nur im gesetzlichen Güterstand, sondern auch in einem nach dem Typus der Errungenschaftsgemeinschaft reformierten Wahlgüterstand gelten, der an die Stelle der in der Rechtspraxis längst überlebten BGB-Gütergemeinschaft treten könnte. ${ }^{69}$ Ein Teil des Unmuts am gesetzlichen Güterstand hat sich gerade an den „überschießende[n] Beteiligungsergebnisse[n] “70 entzündet, zu denen insbesondere auch der nach $\mathbb{} 1374$

67 Deutscher Familiengerichtstag e.V. (Hrsg.), Sechzehnter Deutscher Familiengerichtstag, Bielefeld 2006, S. 165f. (Arbeitskreis 21, Empfehlung V).

68 Vgl. Dethloff, Ausgleichssysteme (Fn. 7), S. 109.

69 Mecke, Thesen (Fn. 11), S. 128-139, 145-156 mit entsprechenden Vorschlägen de lege ferenda. Ein künftiger Wahlgüterstand der BGB-Errungenschaftsgemeinschaft müsste sich also auch in diesem Punkt unterscheiden vom Wahlgüterstand der Errungenschaftsgemeinschaft, den das BGB in der Fassung von 1896 vorsah. Der reformbedürftige Zuschnitt der Vermögensteilhabe im heutigen gesetzlichen Güterstand nach $\$ 1374$ Abs. 2 BGB rührt nämlich noch unmittelbar her von der entsprechenden Vorschrift in $\$ 1521$ BGB a.F. zur einstigen BGB-Errungenschaftsgemeinschaft [Meder, Grundprobleme (Fn. 28), S. 33-45].

70 Schwab, Vermögensausgleich (Fn. 64), S. 54. 
Abs. 2 BGB noch nicht mögliche konsequente Ausschluss offensichtlich nicht ehebedingten Erwerbs gehört. ${ }^{71}$

Auf jeden Fall kann man gegenwärtig schon sagen, dass der im geltenden deutschen Unterhaltsrecht inzwischen ausdrücklich in das Gesetz aufgenommene Gedanke der Ehebedingtheit ${ }^{72}$ auch in der güterrechtlichen Diskussion zunehmend an Bedeutung erlangt. Dieser Umstand ist Ausdruck einer offenbar allgemein im Vordringen befindlichen Sichtweise, die weniger generell-typisierend als stärker konkret-individualisierend auf die tatsächlichen Ursachen von Vermögenszuwächsen in der Ehe bzw. Lebenspartnerschaft gerichtet ist. ${ }^{73}$ Die im September 2009 in Kraft getretene gesetzliche Reform des Zugewinnausgleichs ist teilweise, nämlich im Hinblick auf die neue rechtliche Möglichkeit der Berücksichtigung eines defizitären Anfangsvermögens eines der beiden Partner bereits Ausdruck der veränderten Sichtweise. Mit der güterrechtlichen Anerkennung eines zunächst defizitären Anfangsvermögens des Ausgleichsverpflichteten werden nämlich ökonomische Tatsachen wie der mutmaßliche Beitrag des Ausgleichsberechtigten zur effektiven Verbesserung der Vermögensbilanz während der Dauer des Güterstandes fortan nicht mehr aufgrund des Gedankens einer sogar voreheliche Schulden einbeziehenden „Lebens- und Schicksalsgemeinschaft" ${ }^{\text {"74 }}$ güterrechtlich ignoriert.

Die Kritik am Umfang der güterrechtlichen Teilhabe des gesetzlichen Güterstandes beschränkt sich inzwischen nicht mehr nur auf die typisierend normative Sichtweise bei der Feststellung der Grenzen zwischen güterrechtlich unbeachtlichem Individualvermögen und auszugleichenden Vermögenswerten. Auch die typisierende Festlegung der Aufteilungsquote für die beiderseitige Teilhabe am vergemeinschafteten Vermögen nach dem schematischen Halbteilungsgrundsatz wird infrage gestellt. So kritisiert Thomas Rauscher angesichts einer „das Eherecht in jüngerer Zeit mehr und

71 Vgl. im Zusammenhang mit der Kontroverse um $\mathbb{S} 1374$ Abs. 2 BGB, die eher eine geballte Kritik an Gesetzgebung und Rechtsprechung als eine Kontroverse innerhalb der Rechtswissenschaft ist, die Nachweise bei Meder, Grundprobleme (Fn. 28), S. 30f. Danach konnte in der „neueren Literatur“ für „die Jahre 2008 und 2009 [...] keine einzige Stimme ausfindig“ gemacht werden, die „eine Ausgleichspflicht des eheneutralen Erwerbs als mit den Prinzipien des Zugewinnausgleichs vereinbar oder ,gerecht' verteidigt hätte.".

72 Nicht das Wort, wohl aber der Begriff findet sich in der bereits zitierten Regelung des $\mathbb{1 5 7 8 \mathrm { b }}$ Abs. 1 Satz 2 BGB, wonach vor einer Herabsetzung oder zeitlichen Begrenzung des nachehelichen Unterhalts ,insbesondere zu berücksichtigen ist, inwieweit durch die Ehe Nachteile“ im Hinblick auf den eigenen Unterhaltserwerb eingetreten sind.

73 Vgl. M. Wellenhofer, Unterhalt, Zugewinn- und Versorgungsausgleich - Sind unsere familienrechtlichen Ausgleichssysteme noch zeitgemäß?, Jura 2008, S. 647 (651) dazu, dass nach dem noch geltenden Recht des BGB-Zugewinnausgleichs die „gesamte gemeinsame Lebensleistung [...] ausgeglichen “ werde: „Auf den Grund des Erwerbs, den Ausbildungsstand der Ehegatten, die Art der ehelichen Arbeitsteilung oder die Dauer der Ehe kommt es nicht an. [...] Dieses Grundkonzept wird seit Langem angegriffen. Die den Zugewinn legitimierenden Gedanken geraten bei einem so weit reichenden Ausgleich eben doch aus dem Blick.".

74 Lieb, Ehegattenmitarbeit (Fn. 45), S. 158. 
mehr beherrschenden Gleichwertigkeits- und Halbteilungsseligkeit " 75 den güterrechtlichten Halbteilungsgrundsatz als „eine standardisierte Typisierung [...], die weniger der Beitragsgerechtigkeit verpflichtet ist als dem Dogma der gemeinsamen Lebensleistung. “76 Demgegenüber gehen Gesetzgebung und Rechtsprechung weiterhin von der im Einzelfall nicht widerlegbaren Vermutung aus, dass beide Güterstandsbeteiligten abgesehen von der Erfüllung ihrer unterhaltsrechtlichen Pflichten ${ }^{77}$ auch durch andere insbesondere vermögensrelevante Entscheidungen wie die Bereitschaft zum Konsumverzicht, Geschicklichkeit bei Geldanlagen oder die Wirtschaftlichkeit von Anschaffungen einen möglicherweise sehr unterschiedlichen, aber doch güterrechtlich gleichwertigen Beitrag zu dem in der Ehe erwirtschafteten $\mathrm{Zu}$ gewinn leisten. ${ }^{78}$

Selbst wenn aus individualisierender Sicht auf die konkreten Beiträge der Ehe- bzw. Lebenspartner „Gerechtigkeitsdefizite einer strikt hälftigen Teilung [...] nicht zu leugnen“ sind, zeigt allerdings nach Nina Dethloff der Blick auf andere Rechtssysteme in den Ländern des Common Law, wo die Gerichte ein weites Ermessen bei der Aufteilung des Vermögens haben, dass der „Preis solcher Einzelfallgerechtigkeit [...] hoch “ sein kann. ${ }^{79}$ Viel spricht daher für das Festhalten an einer gesetzlichen Quote, die nach dem Vorschlag von Dethloff jedoch ,in bestimmten Fällen, in denen typischerweise die Vermögensdifferenz nicht ehebedingt ist“, etwa bei Kurzehen ohne Kinder, eine Flexibilisierung zulassen sollte. ${ }^{80}$ Bezeichnenderweise kommt inzwischen selbst in der englischen Rechtsordnung, die kein gesondertes gesetzliches Güterrecht, aber seit 1973 ein System der scheidungsbedingten Vermögens- und Einkommensaufteilung mit gerichtlichem Ermessensspielraum kennt, ${ }^{81}$ in der Rechtsprechungspraxis, „wenn auch zunächst vor allem in ,big money cases““, zunehmend der Halbteilungsgrundsatz zum Tragen. ${ }^{82}$

75 T.Rauscher, Ehevereinbarungen: Die Rückkehr der Rechtssicherheit, DNotZ 2004, S. 524 (528).

76 T.Rauscher, Technische Reform der Zugewinngemeinschaft - zu kurz gegriffen, in: W.Bayer/E.Koch (Hrsg.), Aktuelle Fragen des Familienrechts, Jena 2009, S. 9 (11).

77 Vgl. insoweit $\mathbb{\$} 1360,1360$ a BGB sowie $\$ 5$ LPartG, wonach die Ehegatten bzw. Partner einer eingetragenen Lebenspartnerschaft unterhaltsrechtlich einander verpflichtet sind, „durch ihre Arbeit und mit ihrem Vermögen die Familie“ bzw. „die partnerschaftliche Lebensgemeinschaft angemessen zu unterhalten“, also die „Kosten des Haushalts zu bestreiten und die persönlichen Bedürfnisse der Ehegatten und den Lebensbedarf der gemeinsamen unterhaltsberechtigten Kinder zu befriedigen ", und wo gleichzeitig „die Führung des Haushalts“ als „in der Regel“ ausreichend zur Erfüllung dieser Pflichten bezeichnet wird.

78 M.Klein, Reform der Zugewinngemeinschaft 2009, Bonn 2010, S. 16.

79 Dethloff, Ausgleichssysteme (Fn. 7), S. 107.

80 Dethloff, Ausgleichssysteme (Fn. 7), S. 109.

81 A.Barlow, Rollenleitbilder im Familienrecht des Vereinigten Königreichs - Probleme der Bewertung von Familienarbeit in und außerhalb der Ehe, in: BMFSFJ (Hrsg.), Dokumentation (Fn. 16), S. 238.

82 Martiny, Schlussfolgerungen (Fn. 16), S. 441. 


\section{Begründungsmodell güterrechtlicher Teilhabe aufgrund einer Kompensation ehe- und partnerschaftsbedingter Nachteile}

Im Zusammenhang mit der Kritik an der rechtlichen Gleichsetzung ungleicher und im Einzelnen auch kaum belegbarer Beiträge zum Vermögenserwerb steht ein alternatives drittes Begründungsmodell für güterrechtliche Teilhabe nach Beendigung des Güterstandes. Es setzt an die Stelle güterrechtlicher Teilhabe an den während der Dauer des Güterstandes erwirtschafteten Vermögensvorteilen des Ausgleichsverpflichteten oder - im Falle eines Gemeinschaftsgüterstandes - an der gemeinsamen Errungenschaft die Kompensation von einseitig erlittenen Vermögensnachteilen des Ausgleichsberechtigten. ${ }^{83}$ Hinter der Idee einer Beschränkung auf den Ausgleich von Vermögensnachteilen steht die für sich genommen heute unumstrittene Einsicht, dass Haushaltsführung und Kinderbetreuung, aber auch andere mit Blick auf den Vermögenserwerb des Ehe- bzw. Lebenspartners getroffene Entscheidungen zum Verzicht oder Aufschub oder zur Beschränkung eigener Erwerbsmöglichkeiten vermögensrechtliche Nachteile nach sich ziehen können, für deren einseitige Hinnahme es im Zeichen des Gleichberechtigungsgrundsatzes keine Rechtfertigung gibt.

Daher wird die Notwendigkeit der Kompensation von ehe- und lebenspartnerschaftsbedingten Nachteilen regelmäßig auch von Vertretern anderer Begründungsmodelle zumindest als ein zusätzlicher Grund für güterrechtliche Teilhabe angeführt. ${ }^{84}$ Daran ist zunächst einmal zutreffend, dass in sämtlichen Fällen, in denen die ehe- oder lebenspartnerschaftsbedingten Vermögensvorteile die ehe- oder lebenspartnerschaftsbedingten Vermögensnachteile übersteigen, Teilhabe an den Vorteilen des anderen faktisch immer auch die Kompensation eigener Nachteile bedeutet. Die Frage ist allerdings, ob aus dieser partiellen wertmäßigen Koinzidenz von Kompensation und Teilhabe gefolgert werden kann, dass die Kompensation eigener Nachteile

83 So im Grundsatz bereits Lieb, Ehegattenmitarbeit (Fn. 45), S. 181f. Heute sieht etwa Rauscher, Reform (Fn. 76), S. 23 die jüngste gesetzliche Reform des Güterrechts „in Widerspruch“ stehen „zu dem in der Reform des Unterhaltsrechts 2008 und in der Rechtsprechung des BGH zur Kontrolle von Eheverträgen überdeutlich werdenden Wandel von einem auf undifferenzierter Teilhabe beruhenden Begründungsansatz hin zu einem dem Nachteilsausgleich verpflichteten Verständnis von Ehevermögensrecht". Auch nach Muscheler, Familienrecht (Fn. 19), S. 171 Rn. 336 würde der güterrechtliche Ausgleich, wenn er Kompensation „für den Verzicht des Haushaltsführenden auf eigene Erwerbstätigkeit“ wäre, nur „die Summe des sparfähigen entgangenen eigenen Erwerbseinkommens“ umfassen dürfen. Unklar hingegen Wellenhofer, Ausgleichssysteme (Fn. 73), S. 651, für die einerseits im Sinne der Vorgenannten ein Vermögensausgleich „nur insoweit“ $\mathrm{zu}$ „rechtfertigen ist [...], als ein ehebedingter Erwerbsverzicht stattgefunden hat“, die aber andererseits „wirklich [...] den Ausgleich des gemeinsam Erwirtschafteten" durchführen will.

84 Sogar ausdrücklich für eine Kombination „beide[r] Begründungsansätze“ zum Zugewinnausgleich als „Teilhabe am gemeinsam Erwirtschafteten“ und als Ausgleich für ehebedingte Nachteile Dauner-Lieb/ Sanders, Teilhabe (Fn. 10), S. 143. 
auch die rechtliche causa für die Teilhabe bilde. ${ }^{85}$ Eine Antwort auf diese nur auf den ersten Blick rein theoretische Frage ist auch von unmittelbarer praktischer Relevanz. Die Kompensation ehebedingter Nachteile allein reicht nämlich in vielen Fällen nicht aus als causa für die güterrechtliche Teilhabe an sämtlichen ehebedingten Vermögensvorteilen, die im Moment der Beendigung des Güterstandes noch vorhanden sind. Damit würde die Legitimation güterrechtlicher Teilhabe mit einseitig ehebedingt erlittenen Vermögensnachteilen zu einer „Reduktion der Zugewinngemeinschaft" 86 führen. Eine rechtliche causa für Ausgleichs- oder Auseinandersetzungsansprüche nach Beendigung des Güterstandes bilden ehe- oder partnerschaftsbedingte Vermögensnachteile nämlich nur dann, wenn Voraussetzung und Umfang der Ansprüche auch an diese Vermögensnachteile anknüpfen. Die Teilhabe müsste also auf einen Nachteilsausgleich beschränkt bleiben, wenn die ehe- oder partnerschaftsbedingten Vermögensnachteile des Ausgleichsberechtigten im Einzelfall geringer sind als die ehe- oder partnerschaftsbedingten Vermögensvorteile des Ausgleichsverpflichteten.

Manfred Lieb, der bereits 1970 die „verbreiteten Theorie[n] der Mitverursachung“ als Legitimation des Zugewinnausgleichs ablehnte und stattdessen anknüpfte am „nicht zuletzt im Interesse des Mannes übernommene[n] Verzicht“ der Ehefrau auf eine eigene ungeschmälerte Erwerbstätigkeit, hat den Schluss auf eine entsprechende Beschränkung der Teilhabe ausdrücklich noch nicht gezogen. Danach sollte „der Ausgleich nicht an dem orientiert werden [...], was die Ehefrau verdient hätte, sondern allein an dem, was in der Ehe - wenn auch allein durch den Mann - tatsächlich verdient worden ist. “ $87 \mathrm{Zu}$ diesem Ergebnis konnte Lieb aber nur kommen, weil er auf den „Fürsorgechararakter" 88 des Zugewinnausgleichs und damit letztlich auf die nacheheliche Solidarität rekurrierte. In der heute hingegen etwa von Rauscher geforderten „Reduktion der Zugewinngemeinschaft“ 89 auf den Nachteilsausgleich tritt eine individualisierend-ökonomische Betrachtung an die Stelle nachehelicher Solidarität. Diese Sichtweise hat es vereinzelt zwar auch schon früher gegeben, ${ }^{90}$ heute

85 So beispielsweise Schwab, Vermögensausgleich (Fn. 64), S. 36, der meint, „das Prinzip gleicher Teilhabe“ lasse sich aus dem Gedanken eines „Ausgleich[s] ehebedingten Erwerbsverzichts“ ableiten, „solange sich die Vermögensbildung im Rahmen angemessener familiärer Vermögensvorsorge bewegt." Kritisch dagegen Rauscher, Reform (Fn. 76), S. 11 zu allen Begründungsansätzen, die den „Ausgleich ehebedingter Erwerbsnachteile [...] nur als Hilfsargument“ zur Legitimation güterrechtlicher Teilhabe verwenden.

86 Rauscher, Reform (Fn. 76), S. 23.

87 Lieb, Ehegattenmitarbeit (Fn. 45), S. 183.

88 Lieb, Ehegattenmitarbeit (Fn. 45), S. 183.

89 Rauscher, Reform (Fn. 76), S. 23.

90 Vgl. nur Lieb, Ehegattenmitarbeit (Fn. 45), S. 183 mit Verweis auf entsprechende Vorschläge von Franz Bydlinski für das österreichische Recht. 
kann sie sich aber auf veränderte soziale Einstellungen berufen, nach denen die Bereitschaft zur nachehelichen Solidarität immer weniger Akzeptanz findet. ${ }^{91}$

Die Bemessung des Nachteilsausgleichs müsste damit aus individualisierend-ökonomischer Perspektive immer konkret im einzelnen Fall und individuell bezogen auf die ehe- bzw. partnerschaftsbedingt erlittenen Vermögensnachteile des Ausgleichsberechtigten erfolgen. Mit schematischen Regelungen wie der generellen Aufteilung vergemeinschafteten Vermögens nach dem Halbteilungsgrundsatz wäre der Nachteilsausgleich dann generell unvereinbar, es sei denn, man fügte der Fiktion einer gleichen Verursachung von Vermögensvorteilen während des Güterstandes noch die zusätzliche Fiktion hinzu, dass „die auf Grund der Arbeitsteilung dem Partner erwachsenden Nachteile [...] grundsätzlich nur die Kehrseite der beim anderen Partner entstehenden Vorteile“ darstellen. ${ }^{92}$

Aber auch ein Wandel güterrechtlicher Teilhabe zum individualisierend-ökonomischen Nachteilsausgleich sähe sich einer Reihe von Fragen ausgesetzt. Das betrifft in Deutschland erstens die Frage nach der Übereinstimmung einer derartigen gesetzlichen Regelung mit der Verfassung angesichts der Tatsache, dass das Bundesverfassungsgericht ohne Rekurs auf nacheheliche Solidarität, Verantwortung oder Bedürftigkeit des Ehegatten ${ }^{93}$ aus Art. 6 Abs. 1, Art. 3 Abs. 2 GG einen verfassungsrechtlichen „Anspruch auf gleiche Teilhabe am gemeinsam Erwirtschafteten“ postuliert. ${ }^{94}$ Zweitens stellt sich die Frage nach einer Abgrenzung des güterrechtlichen Ausgleichs zum Recht des nachehelichen Unterhalts, der durch Gesetzgebung und Rechtsprechung in Zukunft voraussichtlich noch stärker auf den die Dauer des Unterhalts beschränkenden Gedanken der Kompensation ehebedingter Nachteile ausgerichtet wird. Drittens bleibt zu fragen, warum zumindest nachweislich ehebedingte Vermögenszuwächse nicht auch einen Anspruch auf gemeinsame Teilhabe an diesen Vermögensvorteilen in Gänze nach sich ziehen sollten, selbst wenn die ebenfalls ehebedingten Vermögensnachteile wertmäßig geringer ausfallen. Eine vollständige Umstellung „der rechtfertigenden Grundlage hin zum Nachteilsausgleich “ würde im Grunde nur in Umkehrung des ,idealisierenden Postulats der gemeinsamen Mitverursachung“ Gefahr laufen, lediglich einen anderen Falltypus kontrafaktisch zu ver-

91 Vgl. nur die oben in Fn. 8 angeführte sozialempirische Studie.

92 So allerdings in der Tat Dethloff, Ausgleichssysteme (Fn. 7), S. 89. Dethloff räumt zwar ein, dass eine „Kompensation für den Verzicht [...] keine Teilhabe“ rechtfertige, wenn diese Teilhabe im konkreten Fall zur „Überkompensation der Nachteile“ führe oder aber umgekehrt „die Nachteile des Erwerbsverzichtenden nur unzureichend kompensiert werden. “ $\mathrm{Da}$ aber „empirisch gesehen [...] in der überwiegenden Zahl der Fälle Partner mit vergleichbarer beruflicher Qualifikation" heiraten, soll man nach Dethloff den güterrechtlichen Teilhabeanspruch mit dem typisierten Fall „von gleich qualifizierten Partnern mit gleicher Entlohnung und gleichen Chancen" begründen können.

93 Wie Dauner-Lieb/Sanders, Teilhabe (Fn. 10), S. 143 hervorheben.

94 Vgl. oben Fn. 9. Schon im Ehevertragsrecht sind die Spannungen zwischen diesem Teilhabeprinzip und Beschränkungen der Teilhalbe nicht gänzlich auflösbar [Schwab, Teilhabe (Fn. 20), S. 1244-1254]. Das würde erst recht für eine gesetzliche Regelung gelten. 
allgemeinern, nämlich den Fall, dass der Ehe- bzw. Lebenspartner gar nicht willens oder „in der Lage ist, maßgeblich den anderen bei dessen Erwerb zu fördern“.95 Viertens würde sich bei einer konsequenten Umstellung auf den Nachteilsausgleich in den Fällen, in denen die erlittenen Vermögensnachteile des einen Güterstandsbeteiligten die ehebedingten Vermögensvorteile des anderen vielleicht sogar deutlich übersteigen, für den Kompensationsberechtigten die Frage stellen, warum er mit seinem Anspruch auf die in der Ehe erlangten Vermögensvorteile beschränkt werden und damit ungeachtet möglicherweise vorhandenen Vermögens beim Ex-Partner keinen umfassenden Kompensationsanspruch haben soll.

\section{E. Resümee}

Resümierend lässt sich feststellen, dass von den drei diskutierten Begründungsmodellen güterrechtlicher Teilhabe dem ganz mehrheitlich vertretenen zweiten Modell einer Anknüpfung der Vermögensteilhabe an die im weitesten Sinne verstandene eigene Leistung bei der Vermögensbildung nach wie vor der Vorzug gebührt (D. II.). Hingegen weist das Begründungsmodell, nach dem güterrechtliche Teilhabe nur noch als Kompensation ehe- und partnerschaftsbedingter Nachteile verstanden wird, nicht nur de lege lata prinzipielle Schwächen auf (D. III.). Mag die Kritik an jeder Art von Vorteilsausgleich gegenwärtig noch Ausdruck vereinzelter Stimmen sein, so lässt sich jedoch auch bei den Diskussionen um die möglichst präzise Abgrenzung von ehebedingtem und eheneutralem Vermögenserwerb eine Tendenz zum individualisierend-ökonomischen Denken feststellen. Diese Tendenz ist nicht auf das Güterrecht beschränkt, wie die Diskussionen und jüngeren Reformen zum Recht des nachehelichen Unterhalts ${ }^{96}$ und zu den familienrechtlichen Ausgleichssystemen im Ganzen ${ }^{97}$ zeigen. Offensichtlich deutet sich hier ein grundsätzlicher Wandel vom solidarisch-typisierenden zum individualisierend-ökonomischen Denken auch im Eherecht an. Nicht vereinbar mit diesem stärker individualisierenden Denken ist ein Begründungsmodell, das die güterrechtliche Teilhabe an den Gedanken der Partnerschaft als einer unbedingten Schicksals- oder Konsumgemeinschaft knüpft (D. I.). Aber auch im Rahmen güterrechtlicher Teilhabe aufgrund der Mitverursachung von Vermögensvorteilen bedarf es bei der Festlegung des Umfangs der Vermögensteilhabe einer deutlich konsequenteren Ausrichtung auf das Kriterium der Ehe- bzw.

95 Rauscher, Reform (Fn. 76), S. 11 sieht aber eben unter dieser Prämisse Anlass, „über weiteren Reformbedarf [...] nachzudenken.".

96 Vgl. nur V.Lipp, Solidarität und Status im Unterhaltsrecht, in: V.Lipp/A.Röthel/Peter A. Windel (Hrsg.), Familienrechtlicher Status und Solidarität, Tübingen 2008, S. 53 (75-77); M.Kremer, Das Prinzip der familiären Solidarität im Unterhaltsrecht des BGB - mit Schwerpunkt nachehelicher Unterhalt, Bielefeld 2010.

97 Dethloff, Ausgleichssysteme (Fn. 7), Gutachten A; E.Koch, Unterhalt, Zugewinn, Versorgungsausgleich - Sind unsere familienrechtlichen Ausgleichssysteme noch zeitgemäß?, in: Juristische Rundschau 2008, S. 309-312; K.Koppenfels-Spies, Unterhalt, Zugewinn, Versorgungsausgleich - Sind unsere familienrechtlichen Ausgleichssysteme noch zeitgemäß?, in: Juristenzeitung (JZ) 2008, S. 801-811; Wellenhofer, Ausgleichssysteme (Fn. 73), S. 647-653. 
Partnerschaftsbedingtheit als im heute in Deutschland geltenden Recht. In diesem Sinne sollte im gesetzlichen Güterstand insbesondere während der Dauer des Güterstandes erfolgter Vermögenserwerb von der güterrechtlichen Teilhabe ausgeschlossen werden, der „nach seiner Zweckbestimmung in keiner Beziehung zur ehelichen Lebens- und Wirtschaftsgemeinschaft steht". ${ }^{98}$

Geschichtlich neu ist ein verstärkt ökonomisches Denken im Zusammenhang mit Ehe und Familie allerdings nicht. Blickt man nämlich in der Geschichte weiter zurück, so sieht man, dass die Ehe vom Mittelalter bis zum Aufkommen des Leitbildes der bürgerlichen Ehe Ende des 18. Jahrhunderts noch sehr viel stärker durch ökonomische Zusammenhänge bestimmt war als heute. ${ }^{99}$ Aus dieser Perspektive könnte man im Anschluss an Dieter Schwab allenfalls von einer „Re-Ökonomisierung der Ehe" 100 als Ausdruck der inzwischen selbst die innerehelichen Beziehungen erfassenden Individualisierungstendenzen sprechen. Allerdings würde auch dies nur einen Ausschnitt aus der partnerschaftlichen Lebenswirklichkeit erfassen. Familiensoziologische Untersuchungen aus jüngerer Zeit zeigen, dass familiale Solidarität, den bereits im 19. Jahrhundert aufkommenden Thesen vom Verfall der Familie zum Trotz, ${ }^{101}$ keineswegs generell zurückgeht, sondern sich vielmehr nur wandelt ${ }^{102}$ und auf bestimmte Lebensabschnitte, etwa die Dauer einer ehelichen Verbindung, konzentriert. ${ }^{103}$ Außerdem folgt auch innerhalb eines Lebensabschnitts aus der emotional begründeten Lebensgemeinschaft nicht mehr wie zu Zeiten, in denen das Verständnis der Ehe als umfassender Schicksalsgemeinschaft noch ungebrochen war, regelmäßig auch die Bereitschaft zu einer Vermögensgemeinschaft. Vor allem aber kann ein Partner nach Beendigung des Güterstands nicht mehr auf eine „überzogene nacheheliche Solidarität“ 104 des anderen hoffen, zumal nachfolgende Ehen oder ein-

98 Vgl. Fn. 67.

99 Vgl. den Kurzüberblick bei E.Völmicke/G.Brudermüller, Einleitung, in: E.Völmicke/G.Brudermüller, Familie - ein öffentliches Gut? Gesellschaftliche Anforderungen an Partnerschaft und Elternschaft, Würzburg 2010, S. 7-10.

100 Schwab, Teilhabe (Fn. 20), S. 1254-1257.

101 R.Habermas, Bürgerliche Kleinfamilie - Liebesheirat, in: R.v.Dülmen (Hrsg.), Entdeckung des Ich. Die Geschichte der Individualisierung vom Mittelalter bis zur Gegenwart, Köln/Weimar/Wien 2001, S. 287 mit Verweis auf den Frühsoziologen Heinrich Riehl, der seine These vom Verfall der Familie bereits Mitte des 19. Jahrhunderts unter anderem mit „unerhörter Individualisierung [...] der weiblichen Natur" erklärte.

102 H.Bertram, Die verborgenen familiären Beziehungen in Deutschland. Die multilokale Mehrgenerationenfamilie, in: M.Kohli/M.Szydlik (Hrsg.), Generationen in Familie und Gesellschaft, Opladen 2000, S. 97-121; C.Posner, Die Bedeutung sozialer Einbindung für die Entwicklung von Individualisierungsprozessen. Eine theoretische Annäherung an das Phänomen der Individualisierung sowie eine empirische Analyse der sozialen Bindungen unter den Bedingungen des sozialen Umbruchs in Deutschland, Frankfurt a.M. u.a. 2002; I.Ostner, Familiale Solidarität, in: J.Beckert/J.Eckert/M.Kohli/W.Streeck (Hrsg.), Transnationale Solidarität. Chancen und Grenzen, Frankfurt am Main 2004, S. 78-94.

103 Vgl. oben Fn. 50.

104 G.Kirchhof, Förderpflicht und Staatsferne. Die aktuellen Reformvorschläge zum Ehegattensplitting, Unterhaltsrecht und Scheidungsverfahren und der grundsätzliche Schutz von Ehe und Familie, FamRZ 2007, S. 241 (245). 
getragene Lebenspartnerschaften neue Solidaritätspflichten gegenüber anderen Partnern erzeugen. Das bedeutet für das Güterrecht, dass die Bestimmung und Akzeptanz der rechtlichen causa für den güterrechtlichen Ausgleich in Zukunft noch wichtiger wird. Denn sie ist es, die in allen auf Vermögensteilhabe ausgerichteten Güterrechtsordnungen die Weichen stellt für den Umfang der Vermögenswerte, die der Teilhabe unterfallen sollen, sowie für die güterrechtliche Funktion dieser Teilhabe. 